\title{
Uma análise histórico-crítica sobre o desenvolvimento das normas brasileiras relacionadas a queijos artesanais
}

\author{
[A critical-historical analysis of the continuous development of Brazilian \\ legislation related to artisanal cheeses]
}

\author{
J.P.A. Araújo, A.C. Camargo, A.F. Carvalho, L.A. Nero*
}

Universidade Federal de Viçosa - Viçosa, MG

\section{RESUMO}

\begin{abstract}
Diferentes tipos de queijos artesanais são produzidos, comercializados e consumidos no Brasil, o que impulsiona o constante desenvolvimento de normas por órgãos oficiais, como o Mapa. A criação do Suasa e do Sisbi-POA foi fundamental para esse setor, por permitir um sistema de equivalência na fiscalização e por ampliar a distribuição. Ainda, o Mapa passou a permitir que queijos artesanais produzidos com leite cru pudessem ser maturados em um período inferior a 60 dias, desde que comprovada sua inocuidade. A redução do tempo de maturação é um tema controverso e polêmico, já que não há critérios específicos que estudos científicos devem contemplar, o que permite múltiplas interpretações de dados. Com a criação e a regulamentação do selo Arte, a fiscalização dos produtos artesanais foi designada aos órgãos de agricultura, pecuária e de saúde pública, em complementação à atribuição já prevista pelo Mapa e pelo Sisbi-POA. Ainda, o selo Arte atribui aos órgãos de inspeção uma função orientadora, atividade que deveria ser prioritariamente executada por agências de extensão e associações. As normas que balizam a produção e comercialização de produtos artesanais devem ser frequentemente atualizadas, devido aos constantes avanços científicos na área e para assegurar a oferta de produtos com qualidade e inócuos aos consumidores.
\end{abstract}

Palavras-chave: queijos artesanais, legislação, fiscalização, comercialização, selo Arte

\begin{abstract}
Different artisanal cheeses are produced, commercialized and consumed in Brazil, leading to a constant development of related rules by the MAPA and other official agencies. The establishment of two national programs (SUASA and SISBI-POA) allowed an equivalence in inspection system and an expanded distribution. Also, MAPA allowed ripening time lower than 60 days for artisanal raw milk cheeses, based on scientific studies that assure their safety. However, lowering the ripening period is still controversial, once there are no proper established criteria for such scientific studies, leading to potential multiple interpretation of data. The newly established ARTE certification transferred the inspection responsibilities of artisanal products to secretaries of agriculture, livestock and health, in support of what was already predicated by MAPA and SISBIPOA. Based on ARTE certification, the inspection service must also provide orientation guidance to producers, which should be done specifically by extension organs and associations. The norms that guide the production and commercialization of these artisanal products often need to be updated, but based on well-established methodologies and procedures, to ensure the distribution of suitable products to consumers.
\end{abstract}

Keywords: artisanal cheese, legislation, inspection, retail sale, ARTE certification

\section{INTRODUÇÃO}

Os dados históricos relacionados à produção de queijos no Brasil são controversos, tanto em relação ao período quanto às regiões em que essa prática foi iniciada. Entretanto, os queijos artesanais brasileiros provavelmente foram originados de Portugal (Dias, 2010; Netto, 2011; Borelli et al., 2016). Desde então, diferentes tipos de queijos artesanais foram desenvolvidos, sendo produzidos principalmente com leite cru. Minas Gerais é o estado com maior produção de queijos no Brasil e foi o primeiro a desenvolver uma legislação própria que viabilizou a produção artesanal de queijos com leite cru (Minas Gerais, 2002b).
A fermentação láctea endógena e a adição de coalho foram processos incorporados nas etapas iniciais de produção dos queijos artesanais. Variações desses procedimentos, como diferentes formas de adição de fermento lácteo, cozimento da massa, prensagem, salga, adição de creme ou gordura e diferentes períodos de maturação, conferem as características peculiares aos queijos artesanais brasileiros (Borelli et al., 2016; Kamimura et al., 2019). Esse modo de produção empírico, passado de geração para geração em famílias de pequenos produtores, determinou diferenças na identidade e nos padrões de qualidade de queijos produzidos artesanalmente em uma mesma região (Perin et al., 2017).

Recebido em 16 de outubro de 2019

Aceito em 12 de março de 2020

*Autor para correspondência (corresponding author)

E-mail:nero@ufv.br 
A cadeia produtiva de queijos artesanais no Brasil não foi adequadamente regulamentada durante décadas, devido a legislações escassas, evasivas ou ineficientes. Nesse período, algumas normas oficiais inviabilizaram a produção artesanal desses produtos (Dores e Ferreira, 2012). Porém, a promulgação da Lei de Indicações Geográficas (IG) e sua aplicação a produtos artesanais, por meio da criação do Sistema Unificado de Atenção à Sanidade Agropecuária (Suasa), além da regulamentação do Sistema Brasileiro de Inspeção de Produtos de Origem Animal (Sisbi-POA) junto ao Ministério da Agricultura, Pecuária e Abastecimento (Mapa), representaram alternativas para a regulamentação da produção e comercialização de queijos artesanais e permitiram o estabelecimento de seus critérios de identidade, qualidade e inocuidade.

Com a atualização do Regulamento de Inspeção Industrial e Sanitária de Produtos de Origem Animal (Riispoa) (Brasil, 2017) e a regulamentação do selo Arte (Brasil, 2018; 2019a), uma série de normas estaduais e municipais relacionadas a produtos artesanais, incluindo queijos, passaram a ser desenvolvidas e implementadas. Essas legislações têm sido criadas com o objetivo de tipificar, padronizar e regulamentar os processos de produção e o comércio de queijos artesanais produzidos por pequenos produtores rurais.

A cadeia produtiva de queijos artesanais no Brasil apresentou uma evolução relevante desde a década de 2000, que foi viabilizada pelo desenvolvimento das normas específicas relacionadas a esses produtos. Porém, diversos aspectos ainda precisam ser aprimorados, como os critérios contemplados pelos estudos científicos, pois eles determinam a identidade, qualidade e inocuidade desses produtos. Considerando que o debate sobre esse tema e a evolução das regulamentações relacionadas são assuntos relevantes, essa pesquisa teve como objetivo realizar uma análise histórica das legislações relacionadas à produção e comercialização de queijos artesanais brasileiros, bem como apresentar uma visão crítica sobre o impacto dessas normas para o setor.

\section{MATERIAL E MÉTODOS}

A análise crítica apresentada nesse artigo foi organizada considerando-se: 1) os principais tipos de queijos artesanais produzidos no Brasil e suas características, 2) uma apresentação histórica das normas relacionadas à produção e comercialização de queijos artesanais brasileiros e 3) uma discussão crítica sobre os desafios e as perspectivas para o desenvolvimento de novas normas e seus potenciais impactos sobre a identidade, qualidade e inocuidade desses produtos.
Dados históricos/científicos relacionados à produção de queijos artesanais no Brasil foram obtidos por meio de consultas bibliográficas nas seguintes plataformas disponíveis on-line: PubMed (https://www.ncbi.nlm.nih.gov/pubmed/), Web of Science (https://www.webofknowledge.com), Scielo (https://www.scielo.org/), ScienceDirect (https://www.sciencedirect.com) e Scopus (https://www.scopus.com). As legislações relacionadas a queijos artesanais foram obtidas em plataformas oficiais: Sistema de Consulta à Legislação do Mapa (http://www.agricultura.gov.br/legislacao-1), Sistema de Legislação da Saúde do Ministério da Saúde (http://www.saude.gov.br/saudelegis), Diário Oficial da União (http://www.in.gov.br) e diários oficiais estaduais (vários).

A pesquisa bibliográfica foi realizada considerando-se aspectos relacionados a queijos artesanais, abrangendo diferentes termos, incluindo "regulamentação, produção, comercialização, consumo, identidade, qualidade higiênica e inocuidade de queijos artesanais". As legislações relacionadas ao tema foram organizadas pelo critério cronológico, o que permitiu uma análise histórico-crítica da evolução das legislações sobre queijos artesanais no Brasil. As referências obtidas foram avaliadas individualmente para seleção daquelas pertinentes ao tema da pesquisa, sendo referenciados documentos publicados entre 1810 e 2020 .

\section{RESULTADO E DISCUSSÃO}

A origem da produção de queijos no Brasil é controversa, devido aos escassos relatos sobre o período inicial da colonização. A atividade pecuária do século XVII foi relatada por Ambrósio Fernandes Brandão (1555-1618), em sua obra "Diálogos das Grandezas do Brasil”, cuja primeira publicação póstuma ocorreu em 1930. Segundo esse autor, praticamente não havia currais naquela época, que eram considerados desnecessários, uma vez que não se produzia queijo ou manteiga (Brandão, 1943).

Por outro lado, Robert Southey relatou que os primeiros queijos já eram produzidos no final do século XVI, na vila de São Salvador, capital da Bahia de Todos os Santos, a partir do leite de vacas, cabras e ovelhas (Southey, 1810; Dias, 2010). Southey (1819) descreveu a produção de queijos também em outros estados do Brasil: Minas Gerais, Pará, Pernambuco, Paraná e Rio Grande do Sul. Dessa forma, as técnicas de produção de queijos se difundiram para outros estados (Fig. 1), originando queijos com diferentes características físicoquímicas, microbiológicas e sensoriais (Borelli et al., 2016; Kamimura et al., 2019). 

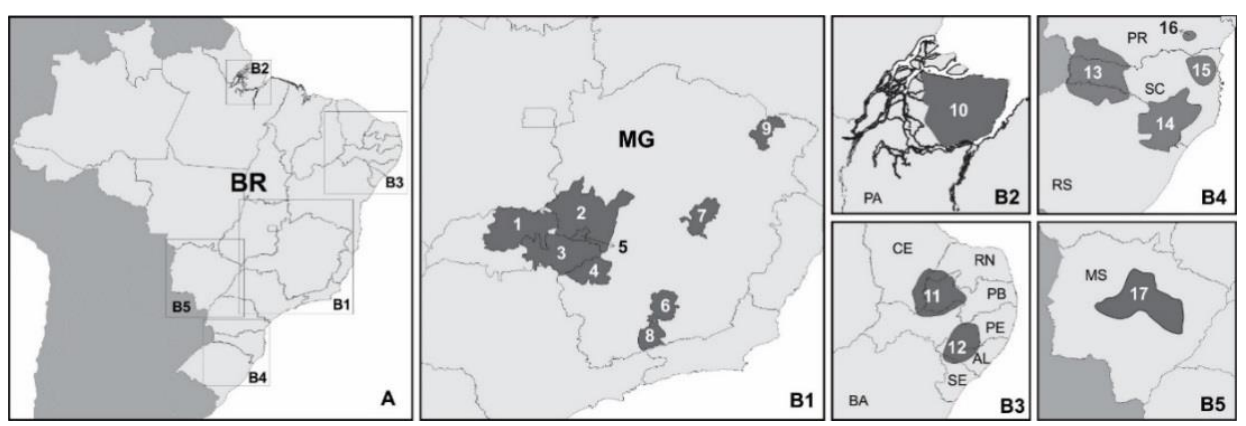

Figura 1. A - principais regiões produtoras de queijos artesanais no Brasil; B1 - variedades de queijos artesanais produzidos em Minas Gerais (MG): Triângulo (1), Cerrado (2), Araxá (3), Canastra (4), Salitre (5), Campo das Vertentes (6), Serro (7), queijo tipo parmesão de Alagoa (parmesão da Mantiqueira) (8) e cabacinha (9); B2 - queijo do Marajó tipo creme e manteiga (10), produzido exclusivamente na Ilha do Marajó, Pará; B3 - coalho e manteiga (11 e 12), produzidos em Ceará (CE), Pernambuco (PE), Rio Grande do Norte (RN), Sergipe (SE), Alagoas (AL) e Paraíba (PB); B4 - colonial (13), produzido em Paraná (PR), Rio Grande do Sul (RS) e Santa Catarina (SC), queijo serrano (14), produzido em RS e SC, queijo kochkäse (15), produzido em SC, e queijo colônia de Witmarsum (16), produzido em PR; B5 - caipira (17), produzido em Mato Grosso do Sul (MS).

Minas Gerais tem sido o estado que mais se destaca na produção de queijos artesanais. Os primeiros relatos sobre o queijo minas indicam que esse produto não serviu apenas como alimento para subsistência, mas também como fonte complementar de renda para as famílias das propriedades rurais que os produziam (Instituto..., 2014; Meneses, 2006). Com o passar dos séculos, o "modo artesanal de fazer o queijo minas" foi passado de geração a geração até os dias atuais. Em 2008, os queijos mineiros das regiões do Serro, da Serra da Canastra e da Serra do Salitre (Alto Paranaíba) foram reconhecidos como patrimônio cultural imaterial pelo Instituto do Patrimônio Histórico e Artístico Nacional (Iphan) (Iphan, 2008).
O queijo minas produzido em diferentes regiões possui etapas de fabricação similares (Borelli et al., 2016; Instituto..., 2014; Meneses, 2007). Porém, esses queijos apresentam características sensoriais distintas, devido a particularidades de produção e características específicas dos locais em que são produzidos. $\mathrm{O}$ modo de produção associado a padrões culturais e regionais, além de características geoclimáticas, determinam a composição de microbiomas específicos e designaram a identidade dos diferentes tipos de queijos artesanais, que são produzidos em diferentes regiões do Brasil (Tab. 1).

\begin{tabular}{|c|c|c|c|c|c|c|c|}
\hline Estado & $\begin{array}{l}\text { Queijos } \\
\text { artesanais }\end{array}$ & Origem & Leite & Maturação & Principais características & IG & Referências \\
\hline \multirow[t]{6}{*}{ MG } & Serro & vaca & cru & $\begin{array}{l}\text { mínimo } \\
17 \text { dias }\end{array}$ & $\begin{array}{l}\text { - Cor branco-amarelada, cilíndrico, } \\
\text { diâmetro de } 13-15 \mathrm{~cm} \text { e altura de } 4-6 \mathrm{~cm} \text {. } \\
\text { - Possui casca lisa, peso de } 0,7-1,0 \mathrm{~kg} \text { e } \\
\text { sabor ligeiramente ácido. }\end{array}$ & $\operatorname{sim}$ & $\begin{array}{l}\text { Instituto..., (2017); Instituto..., } \\
\text { (2019b); Kamimura } \text { et al. } \\
\text { (2019); Machado et al. (2004); } \\
\text { Martins et al. (2015); Minas } \\
\text { Gerais (2018). }\end{array}$ \\
\hline & Canastra & vaca & cru & $\begin{array}{l}\text { mínimo } \\
22 \text { dias }\end{array}$ & $\begin{array}{l}\text { - Cor branco-amarelada, cilíndrico, } \\
\text { diâmetro de } 15-17 \mathrm{~cm} \text { e altura de } 6-9 \mathrm{~cm} \text {. } \\
\text { - Consistência semidura ou ligeiramente } \\
\text { macia, peso de } 1,0-1,3 \mathrm{~kg} \text { e sabor } \\
\text { suavemente ácido. }\end{array}$ & $\operatorname{sim}$ & $\begin{array}{l}\text { Bemfeito et al. (2016); Dores } \\
\text { et al. (2013); Instituto..., } \\
\text { (2017); Instituto..., (2019b); } \\
\text { Kamimura } \text { et al. (2019); Minas } \\
\text { Gerais (2018); Slow Food } \\
\text { (2019). }\end{array}$ \\
\hline & Araxá & vaca & cru & $\begin{array}{l}\text { mínimo } \\
14 \text { dias }\end{array}$ & $\begin{array}{l}\text { - Cor branca, cilíndrico, diâmetro de } 14- \\
17 \mathrm{~cm} \text { e altura de } 4-7 \mathrm{~cm} \text {. } \\
\text { - Consistência varia de semidura a macia, } \\
\text { possui casca fina, amarelada, peso de } \\
1,0-1,2 \mathrm{~kg} \text { e sabor suavemente ácido. }\end{array}$ & - & $\begin{array}{l}\text { Instituto..., (2017); Kamimura } \\
\text { et al. (2019); Minas Gerais } \\
\text { (2018); Slow Food (2019). }\end{array}$ \\
\hline & $\begin{array}{l}\text { Campo das } \\
\text { Vertentes }\end{array}$ & vaca & cru & $\begin{array}{l}\text { mínimo } \\
22 \text { dias }\end{array}$ & $\begin{array}{l}\text { - Cor amarelo-palha, cilíndrico, diâmetro } \\
\text { de } 15 \mathrm{~cm} \text { e altura de } 4 \mathrm{~cm} \text {. } \\
\text { - Possui casca semidura, podendo } \\
\text { apresentar olhaduras, peso de } 0,75 \mathrm{~kg} \text { e } \\
\text { sabor suavemente ácido. }\end{array}$ & - & $\begin{array}{l}\text { Castro } \text { et al. }(2016) ; \\
\text { Instituto..., (2017); Kamimura } \\
\text { et al. }(2019) ; \text { Minas Gerais } \\
(2018) .\end{array}$ \\
\hline & Cerrado & vaca & cru & $\begin{array}{l}\text { mínimo } \\
22 \text { dias }\end{array}$ & $\begin{array}{l}\text { - Cor branco-amarelada, cilíndrico, } \\
\text { diâmetro de } 15 \text { a } 17 \mathrm{~cm} \text { e altura de } 4 \text { a } \\
6 \mathrm{~cm} . \\
\text { - Possui casca semidura, peso de } 1,0 \text { - } \\
1,2 \mathrm{~kg} \text {, sabor suavemente ácido e } \\
\text { consistência, tendendo a macia. }\end{array}$ & - & $\begin{array}{l}\text { Instituto..., (2017); Kamimura } \\
\text { et al. }(2019) ; \text { Minas Gerais } \\
\text { (2018). }\end{array}$ \\
\hline & $\begin{array}{l}\text { Serra do } \\
\text { Salitre }\end{array}$ & vaca & cru & $\begin{array}{l}\text { mínimo } \\
22 \text { dias }\end{array}$ & $\begin{array}{l}\text { - Cor branco-amarelada, cilíndrico, } \\
\text { diâmetro de } 15-17 \mathrm{~cm} \text { e altura de } 4-8 \mathrm{~cm} \text {. } \\
\text { - Consistência semidura, peso de } 1,0- \\
1,3 \mathrm{~kg} \text { e sabor suavemente ácido, não } \\
\text { picante. }\end{array}$ & - & $\begin{array}{l}\text { Instituto..., (2017); Lima et al. } \\
\text { (2008); Minas Gerais (2018); } \\
\text { Slow Food (2019). }\end{array}$ \\
\hline
\end{tabular}




\begin{tabular}{|c|c|c|c|c|c|c|c|}
\hline Estado & $\begin{array}{c}\text { Queijos } \\
\text { artesanais }\end{array}$ & Origem & Leite & Maturação & Principais características & IG & Referências \\
\hline & Triângulo & vaca & cru & $\begin{array}{l}\text { mínimo } \\
22 \text { dias }\end{array}$ & $\begin{array}{l}\text { - Cor amarelo-ouro, casca semidura e } \\
\text { textura compacta. } \\
\text { - Sabor é pouco pronunciado e } \\
\text { suavemente ácido. }\end{array}$ & - & $\begin{array}{l}\text { Instituto..., (2017); Minas } \\
\text { Gerais (2018). }\end{array}$ \\
\hline & Cabacinha & vaca & $\begin{array}{l}\text { cru } \\
\text { (massa } \\
\text { passa por } \\
\text { filagem) }\end{array}$ & ND & $\begin{array}{l}\text { - Cor branco-amarelada, apresentando-se } \\
\text { amarelo-palha quando envelhecido. } \\
\text { - Formato se assemelha a uma cabaça. } \\
\text { - Pode ser considerado um queijo de } \\
\text { requeijão esticado, suave e compacto; } \\
\text { seu sabor é mais pronunciado com o } \\
\text { envelhecimento. }\end{array}$ & - & $\begin{array}{l}\text { Brasil (2011, 2017); Santos } \\
\text { Filho et al. (2016); Instituto..., } \\
\text { (2014b, 2017); Minas Gerais } \\
\text { (2018); Slow Food (2019). }\end{array}$ \\
\hline & $\begin{array}{l}\text { Alagoa } \\
\text { (Parmesão da } \\
\text { Mantiqueira) }\end{array}$ & vaca & $\begin{array}{l}\text { cru } \\
\text { (massa } \\
\text { passa por } \\
\text { cozimento) }\end{array}$ & ND & $\begin{array}{l}\text { - Cor amarela palha, cilíndrico, diâmetro } \\
\text { de } 15-30 \mathrm{~cm} \text {. } \\
\text { - Possui casca lisa, massa compacta, com } \\
\text { pequenas olhaduras, sabor forte e } \\
\text { salgado, sendo acentuado quando } \\
\text { envelhecido. }\end{array}$ & & $\begin{array}{l}\text { Brasil }(2011,2017) ; \\
\text { Instituto..., (2014a, 2017); } \\
\text { Minas Gerais (2018); Pinto et } \\
\text { al. (2015); Slow Food (2019). }\end{array}$ \\
\hline PR & $\begin{array}{l}\text { Colonial, da } \\
\text { "Colônia de } \\
\text { Witmarsum" }\end{array}$ & vaca & $\begin{array}{l}\text { Pasteu- } \\
\text { rizado }\end{array}$ & $\begin{array}{l}20-28 \\
\text { dias }\end{array}$ & $\begin{array}{l}\text { - Cor amarela, massa semimole, podendo } \\
\text { apresentar olhaduras. } \\
\text { - Casca de coloração amarela intensa, } \\
\text { devido à aplicação de urucum. }\end{array}$ & $\operatorname{sim}$ & $\begin{array}{l}\text { Instituto..., (2019b); Paraná } \\
\text { (2018). }\end{array}$ \\
\hline $\begin{array}{l}\text { PR, } \\
\text { RS, } \\
\text { SC }\end{array}$ & Colonial & vaca & cru & ND & $\begin{array}{l}\text { - Cor amarelo-palha, casca fina, } \\
\text { uniforme e lisa. } \\
\text { - Pode apresentar dimensões variáveis e } \\
\text { olhaduras de acordo com a região } \\
\text { produtora, possuindo sabor pronunciado. }\end{array}$ & - & $\begin{array}{l}\text { Brasil (2011, 2017); Fava et al. } \\
\text { (2012); Kamimura et al. } \\
\text { (2019); Paraná (2018); Rio } \\
\text { Grande do Sul (2018); Santa } \\
\text { Catarina (2018); Slow Food } \\
\text { (2019). }\end{array}$ \\
\hline $\begin{array}{l}\mathrm{RS}, \\
\mathrm{SC}\end{array}$ & Serrano & vaca & cru & $\begin{array}{l}60 \\
\operatorname{dias}^{1}\end{array}$ & $\begin{array}{l}\text { - Queijo semiduro de baixo teor de } \\
\text { umidade e peso de } 1,0-2,5 \mathrm{~kg} \text {. } \\
\text { - Possui sabor acentuado, sendo } \\
\text { envelhecido em prateleiras de madeira. }\end{array}$ & - & $\begin{array}{l}\text { Brasil (2011, 2017); } \\
\text { Kamimura et al. (2019); Santa } \\
\text { Catarina (2018); Rio Grande } \\
\text { do Sul (2018); Cruz e } \\
\text { Menasche (2014); Rio Grande } \\
\text { do Sul (2019); Slow Food } \\
(2019) .\end{array}$ \\
\hline SC & kochkäse & vaca & $\begin{array}{l}\text { cru ou } \\
\text { pasteu- } \\
\text { rizado }\end{array}$ & ND & $\begin{array}{l}\text { - Coagulação natural do leite. } \\
\text { - Passa por um período de repouso de } 2 \text { a } \\
7 \text { dias, seguido de cozimento. }\end{array}$ & - & $\begin{array}{l}\text { Brasil }(2011,2017) ; \text { Santa } \\
\text { Catarina (2018); Slow Food } \\
\text { (2019). }\end{array}$ \\
\hline MS & Caipira & vaca & cru & ND & $\begin{array}{l}\text { - Consistência firme, massa uniforme, } \\
\text { podendo apresentar olhaduras mecânicas. }\end{array}$ & - & $\begin{array}{l}\text { Agência..., (2019); Kamimura } \\
\text { et al. (2019); Mato Grosso do } \\
\text { Sul (2004); Slow Food (2019). }\end{array}$ \\
\hline $\begin{array}{l}\text { CE, } \\
\mathrm{PE}, \\
\mathrm{PB}, \\
\mathrm{RN} \\
\mathrm{SE}\end{array}$ & Coalho & $\begin{array}{l}\text { vaca, } \\
\text { cabra, } \\
\text { ovelh } \\
\text { a, e } \\
\text { búfala }\end{array}$ & $\begin{array}{l}\text { cru } \\
\text { (cozimento } \\
\text { opcional } \\
\text { da massa) }\end{array}$ & t & $\begin{array}{l}\text { - Formato retangular, consistência } \\
\text { elástica, textura compacta e macia, } \\
\text { apresenta tons suaves de amarelo. } \\
\text { - Paraíba e Pernambuco são os únicos } \\
\text { estados que permitem a utilização, } \\
\text { também, de leites de cabra, ovelha e } \\
\text { búfala. }\end{array}$ & - & $\begin{array}{l}\text { Brasil (2001, 2011, 2017); } \\
\text { Kamimura et al. (2019); } \\
\text { Paraíba (2019); Pernambuco } \\
\text { (2007, 2018); Rio Grande do } \\
\text { Norte (2017); Sergipe (2019); } \\
\text { Lima et al. (2018); Slow Food } \\
\text { (2019). }\end{array}$ \\
\hline $\begin{array}{l}\text { AL, } \\
\text { SE, } \\
\text { PE, } \\
\text { PB, } \\
\text { RN }\end{array}$ & $\begin{array}{l}\text { Manteiga } \\
\text { (Queijo do } \\
\text { Sertão, } \\
\text { Requeijão do } \\
\text { Nordeste) }\end{array}$ & vaca & $\begin{array}{l}\text { cru (massa } \\
\text { cozida e } \\
\text { fundida } \\
\text { com } \\
\text { manteiga) }\end{array}$ & ND & $\begin{array}{l}\text { - As características podem variar de } \\
\text { acordo com o estado ou a região } \\
\text { produtora. }\end{array}$ & - & $\begin{array}{l}\text { Brasil (2001, 2011, 2017); } \\
\text { Kamimura et al. (2019); } \\
\text { Paraíba (2019); Pernambuco } \\
\text { (2007, 2018); Rio Grande do } \\
\text { Norte (2017); Sergipe (2019); } \\
\text { Slow Food (2019). }\end{array}$ \\
\hline PA & $\begin{array}{l}\text { Marajó (tipo } \\
\text { creme e } \\
\text { manteiga) }\end{array}$ & $\begin{array}{l}\text { búfala } \\
\text { e } \\
\text { vaca }\end{array}$ & $\begin{array}{l}\text { cru (massa } \\
\text { cozida e } \\
\text { fundida com } \\
\text { creme ou } \\
\text { manteiga) } \\
\end{array}$ & -3 & $\begin{array}{l}\text { - As características podem variar de } \\
\text { acordo com os processos empregados na } \\
\text { produção. }\end{array}$ & - & $\begin{array}{l}\text { Brasil (2011, 2017); } \\
\text { Kamimura et al. (2019); Pará } \\
\text { (2011); Agência..., (2013). }\end{array}$ \\
\hline \multicolumn{8}{|c|}{$\begin{array}{l}\text { IG - Indicação Geográfica; ND - não determinado; MG - Minas Gerais; MS - Mato Grosso do Sul; PR - Paraná; RS - Rio Grande do Sul; SC - Santa } \\
\text { Catarina; CE - Ceará; AL - Alagoas; SE - Sergipe; PE - Pernambuco; PB - Paraíba; RN - Rio Grande do Norte; PA - Pará.. } \\
\text { 'Definido apenas para o queijo Serrano produzido em SC. }{ }^{2} \text { Comercializado até } 10 \text { dias após a produção. }{ }^{3} \text { Comercializado entre sete e } 30 \text { dias após a } \\
\text { produção. } \\
\text { Adepará, Agência Estadual de Defesa Agropecuária do Estado do Pará; Iagro, Agência Estadual de Defesa Sanitária Animal e Vegetal; Inpi, Instituto } \\
\text { Nacional da Propriedade Industrial; IMA, Instituto Mineiro de Agropecuária; SEAPDR, Secretaria da Agricultura, Pecuária e Desenvolvimento Rural. }\end{array}$} \\
\hline
\end{tabular}

As primeiras normas nacionais que regulamentaram a produção e inspeção industrial de produtos de origem animal no Brasil datam do início do século XX, incluindo a criação de um Serviço de Inspeção Federal Oficial. A criação dessas normas foi estimulada pelo fato de o Brasil ter começado a exportar gêneros alimentícios, devido à escassez de alimentos causada pelas Primeira e Segunda Guerras Mundiais (Battaglini e Fagnari, 2014). Com a criação da Organização das Nações Unidades (ONU) e da Organização das Nações Unidas para Alimentação e Agricultura (FAO), em 1945, e da Organização Mundial da Saúde (OMS), em 1948, houve importante desenvolvimento de políticas 
públicas relacionadas à alimentação e nutrição (Graça e Gregório, 2012; Grieco, 1995).

Nesse contexto, muitos países começaram a atualizar seus regulamentos para garantir a produção de alimentos seguros. Assim, a partir da década de 1950 foram criadas no Brasil sucessivas normas que direcionavam a produção e comercialização de produtos de origem animal, incluindo queijos, sendo inicialmente voltadas para produção industrial. A regulamentação da produção e comercialização dos queijos artesanais foi marginalizada durante muitas décadas, já que as primeiras normas classificavam a produção dos queijos "curados" (queijo minas e queijo de coalho) ainda como incipiente (Battaglini e Fagnari, 2014; Brasil, 1952, 1962).

Essa deficiência nas legislações determinou impactos negativos na qualidade e inocuidade desses produtos, uma vez que manteve o mercado informal. Com o objetivo de garantir a produção de queijos artesanais com preceitos de qualidade e de inocuidade e de viabilizar a comercialização desses produtos, o governo federal (Tab. 2) e diferentes estados brasileiros (Tab. 3) começaram a revisar leis vigentes e criar novas normas a partir da década de 1990 (Brasil, 1989, 1991, 1996a, 2011, 2018, 2019a; Minas Gerais, 2010, 2011). Essas adequações tiveram como objetivo preservar as tradições regionais, garantindo, assim, a produção de alimentos artesanais com respeito às normas sanitárias estabelecidas.

Inicialmente, o Decreto 30.691 (Brasil, 1952) classificou as "queijarias" como estabelecimentos situados em fazendas leiteiras e destinadas à fabricação de queijo minas, e determinou que elas deveriam estar filiadas a entrepostos de leite e derivados registrados. O decreto ainda determinou um período mínimo de três dias para expedição do queijo minas produzido com leite pasteurizado e oito dias para aqueles "curados" (Serro, Araxá e queijo de coalho) (Brasil 1952). No entanto, o Decreto 1.255 (Brasil, 1962) determinou novo período mínimo (10 dias) para expedição dos queijos "curados".

Dessa forma, a abrangência das primeiras normas ficou basicamente restrita ao queijo minas, além disso, praticamente inviabilizou que pequenos produtores de queijos artesanais tivessem acesso ao mercado formal. Já na década de 1990, a Portaria 146, de 1996, teve como objetivo regulamentar importantes padrões técnicos de identidade e qualidade dos produtos lácteos no Brasil (Brasil, 1996a). A vigência da Portaria 146, que determinava período mínimo de maturação de 60 dias para que os queijos produzidos com leite cru fossem comercializados, acabou prejudicando os produtores, uma vez que esse período de maturação poderia comprometer as características sensoriais de alguns tipos de queijos artesanais. Em complementação à Portaria 146, a Resolução 07 (Brasil, 2000) reforçou a necessidade de maturação por, pelo menos, 60 dias e determinou que esse processo fosse realizado em entreposto fiscalizado pelo Serviço de Inspeção Federal (SIF) (Tab. 2)

Em 2006, o Decreto 5.741 (Brasil, 2006) regulamentou as Leis 8.171 (1991) e 9.712 (1998), que organizaram o Sistema Unificado de Atenção à Sanidade Agropecuária (Suasa) e o Sistema Brasileiro de Inspeção de Produtos de Origem Animal (Sisbi-POA). Dessa forma, o Mapa criou um sistema nacional com função de promoção da saúde, com ações de vigilância e defesa sanitária animal intermediadas pelo SisbiPOA. Esses sistemas permitiram a expansão do comércio de alimentos produzidos por indústrias fiscalizadas pelos serviços de inspeção estaduais e municipais, por meio do sistema de equivalência gerenciado pelo Sisbi-POA, o que pode ser considerado como um fator estimulador para produtores que queijos artesanais. Essas ações foram concretizadas com a publicação do Decreto 7.216 (Brasil, 2010), que determinou importantes alterações no Decreto 5.741, permitindo a descentralização do SIF por meio do Suasa, condicionada à prévia autorização pelo Mapa (Tab. 2).

Outra alteração relevante do Decreto 5.741 foi a previsão de que os órgãos de fiscalização estaduais e municipais pudessem agir como regulamentadores na definição de normas específicas aos estabelecimentos de produtos artesanais (Brasil, 2010). Dessa forma, o Mapa viabilizou a ação dos serviços de inspeção estaduais e municipais em pequenos estabelecimentos industriais e propriedades, onde tipicamente queijos artesanais são produzidos no Brasil.

Em relação à maturação dos queijos artesanais produzidos com leite cru, leis federais contemplaram a redução do período previamente fixado em 60 dias (Brasil, 2011; 2013). A atualização do Riispoa (Brasil, 2017) reafirmou a possibilidade de redução do período, determinando a obrigatoriedade da realização de estudos científicos que comprovassem a qualidade e inocuidade do produto maturado nessas condições (Tab. 2). Embora importante, a redução do tempo de maturação é um tema considerado controverso e polêmico, uma vez que não há especificações sobre quais critérios esses estudos científicos devem contemplar, como metodologias e procedimentos, e, assim, permite diferentes interpretações para estudos conduzidos com diferentes critérios. 


\section{Araújo et al.}

Tabela 2. Evolução cronológica e de abrangência da legislação federal relacionada a queijos artesanais produzidos no Brasil

\begin{tabular}{llc}
\hline Legislação & \multicolumn{1}{c}{ Principais diretrizes } & Referências \\
\hline Lei 1.283 & - Dispõe sobre a inspeção industrial e sanitária dos POA. & Brasil (1950) \\
& Art. ${ }^{\circ}$. Estabelece a fiscalizaçâo, industrial e sanitária, dos POA, comestíveis e não comestíveis. & Brasil (1952) \\
Decreto & - Aprova o Regulamento de Inspeção Industrial e Sanitária de Produtos de Origem Animal (Riispoa). &
\end{tabular}

30.691 Art. 928. Classifica as variedades de QMA curados como: semiduro (tipo Serro) e duro (tipo Araxá); queijo de coalho (tipo Nordeste brasileiro), referindo-se a essas variedades como incipientes.

Decreto - Altera o Decreto 30.691.

Brasil (1962)

$\begin{array}{ll}1.255 & \text { - Altera o Decreto } 30.691 .\end{array}$

Art. 4. Delega a fiscalização interestadual e internacional do comércio de POA à União por meio do Mapa; fiscalização do comércio intermunicipal aos órgãos estaduais; e fiscalização do comércio municipal às secretarias de agriculturas dos municípios.

Lei 8.171 - Dispõe sobre a política agrícola no Brasil.

Portaria 146 - Aprova os Regulamentos Técnicos de Identidade e Qualidade dos Produtos Lácteos.

Anexo I. 7.1. Permite a produção de queijos com leite cru, desde que maturados por, pelo menos, 60 dias e, no mínimo, a Anex $1{ }^{\circ} \mathrm{C}$.

Lei 9.279 - Regula direitos e obrigações relativos à propriedade industrial. Título IV. Das Indicações Geográficas:

Art. 176. Constitui indicação geográfica a indicação de procedência ou a denominação de origem.

Lei 9.712 - Altera a Lei 8.171, de 1991, acrescentando-lhe dispositivos referentes à defesa agropecuária.

Resolução - Oficializa critérios de funcionamento e de controle da produção de queijarias junto ao SIF:

07 Anexo I. 5.4. Restringe ao queijo minas a produção com leite cru. Determina a comercializado após 60 dias de maturação em Anexo I. 5.4. Restringe ao queijo minas a produção com leite cru. Determina a comercializado após 60 dias de maturação em
entreposto de laticínios registrado no SIF, de acordo com a Portaria 146/96, a contar da data de chegada naquele estabelecimento.

IN 30 - Aprova Regulamentos Técnicos de Identidade e Qualidade de Manteiga da Terra (de garrafa), Queijo Coalho e Queijo Manteiga.

Decreto - Regulamenta os arts. 27-a, 28-a e 29-a da Lei 8.171, de 1991, referentes ao Suasa.

5.741 Capítulo X. Da inspeção de produtos e insumos agropecuários.

Art. 130. Como parte do Suasa e com o objetivo de inspecionar e fiscalizar os POA, fica constituído o Sisbi-POA.

Decreto - Acresce dispositivos aos arts. 27-A, 28-A e 29-A da Lei 8.171, de 1991, aprovada pelo Decreto 5.741, de 2006.

7.216 Art. $1^{\circ}$. Dispõe nova redação aos arts. $2^{\circ}, 96,149$ e 153 do Decreto 5.741 , de 2006

IN 57 - Dispõe sobre o período de maturação dos queijos artesanais, elaborados a partir de leite cru.

Art. $1^{\circ}$. Permite período de maturação inferior a 60 dias, desde que estudos conduzidos pelo Mapa comprovem a qualidade e a inocuidade do produto.

Art. $2^{\circ}$. Restringe a produção de queijos com leite cru, maturados por menos de 60 dias, a queijarias com indicação geográfica ou tradicionalmente reconhecidas e em propriedades certificadas, oficialmente, como livres de tuberculose e brucelose.

IN 30 - Permite redução de 60 dias de maturação a queijos artesanais se amparada em estudos técnico-científicos.

- Permite redução de 60 dias de maturação a queijos artesanais se amparada em estudos técnico-científicos.
- O novo período de maturação pode ser determinado pelo órgão estadual/municipal de inspeção reconhecido pelo SisbiPOA.

Art. 2. Restringe a produção de queijos com leite cru, maturados por menos de 60 dias, a queijarias com IG ou tradicionalmente reconhecidas em propriedades certificadas como livres de tuberculose e brucelose de acordo com o PNCEBT, ou controladas para brucelose e tuberculose pelo Órgão Estadual de Defesa Sanitária Animal, no prazo de até três anos.

Art. $5^{\circ}$. Fica revogada a IN 57, de 2011.
Lei $9.013 \quad$ - Regulamenta a Lei 1.283 , de 1950, que dispõe sobre a inspeção industrial e sanitária de POA.

Brasil (1989)

Brasil (1991)

Brasil (1996a)

Brasil (1996b)

Brasil (1998)

Brasil (2000)

Brasil (2001)

Brasil (2006)

Brasil (2010)

Brasil (2011)

Brasil (2013)

Capítulo II. Do âmbito de atuação:

Art. $2^{\circ}$. A fiscalização do comércio interestadual ou internacional é de competência do Dipoa e do SIF, vinculados ao Mapa

$\S 1^{\circ} \mathrm{A}$ fiscalização do Mapa objetiva reinspecionar os POA destinados ao comércio interestadual ou internacional em casa atacadistas que recebem e armazenam estes produtos.

$\S 2^{\circ} \mathrm{A}$ fiscalização dos estabelecimentos de POA, com comércio interestadual, poderá ser executada pelos serviços de inspeção dos estados, do Distrito Federal e dos municípios, havendo equivalência de serviços junto ao Mapa, embasados no Suasa.

Capítulo V. Dos padrões de identidade e qualidade de leite e derivados lácteos:

Art. 373.

$\S 6^{\circ}$ Produção de queijos com leite cru: desde que maturados acima de $5^{\circ} \mathrm{C}$, por 60 dias.

$\S 7^{\circ}$ Permite reduzir o tempo de maturação, desde que estudos concluam a inocuidade do produto ou em casos previstos no RTIQ.

Decreto - Altera a Lei 1.283, de 1950, e dispõe sobre a fiscalização de produtos artesanais de origem animal.

$13.680 \quad$ Art. $2^{\circ}$. A Lei 1.283 , de 1950, passa a vigorar acrescida do seguinte art. 10-A:

Art. 10-A. É permitida a comercialização interestadual de produtos alimentícios produzidos de forma artesanal, desde que submetidos à fiscalização de órgãos de saúde pública dos estados e do Distrito Federal.

$\S 1^{\circ} \mathrm{O}$ produto artesanal será identificado, em todo o território nacional, por selo único com a indicação Arte.

$\S 4^{\circ} \mathrm{A}$ inspeção e a fiscalização dos produtos artesanais com o selo Arte deverão ter natureza, prioritariamente, orientadora.

Decreto - Regulamenta o art. 10-A da Lei 1.283, de 1950.

$9.918 \quad$ Art. $6^{\circ}$. Compete aos órgãos de agricultura e pecuária estaduais e distrital:

I - Conceder o selo Arte aos produtos artesanais que atenderem ao disposto neste decreto e nas normas técnicas

I - Conceder o selo Arte aos produtos artesanais que atenderem
complementares.

II - Fiscalizar os produtos artesanais que tenham obtido o selo Arte.

III - Estabelecer normas sanitárias e regulamentos complementares às normas federais que caracterizem e garantam a

inocuidade do produto alimentício artesanal e que contemplem o disposto neste decreto.

IV - Fornecer e atualizar as informações do Cadastro Nacional de Produtos Artesanais.

Art. $7^{\circ}$. A identidade, a qualidade e a segurança serão garantidas pelo produtor.

Art. $8^{\circ}$. Compete aos órgãos de saúde pública estaduais e distrital a fiscalização no comércio varejista e atacadista.

Decreto - Altera o Anexo ao Decreto $\mathrm{n}^{\circ}$ 5.741, de 30 de março de 2006, para dispor sobre as competências dos consórcios públicos

10.032 de município no âmbito do Sisbi-POA.

$\begin{array}{ll}\text { IN } 67 & \text { - Estabelece os requisitos para que os estados e o Distrito Federal realizem a concessão do selo Arte, aos produtos alimentícios } \\ \text { de origem animal produzidos de forma artesanal. }\end{array}$

IN 73 - Normatiza boas práticas agropecuárias na produção de leite destinado à produção de derivados lácteos de forma artesanal. Brasil (2019e)

Origem Animal; PNCEBT - Programa Nacional de Controle e Erradicac̃a Oa Brom Animal; Mapa - Ministério dal; SIF - Serviço de Inspeção Federal; QMA - queijo minas artesanal: RTIQ - Regulamento Técnico de Identidade e Qualidade; Sisbi-POA - Sistema Brasileiro de Inspeção de Produtos de Origem Animal; Suasa - Sistema Unificado de artesanal; RTQ - Regulamento Técnico de Identidade e Qualidade; Sisbi-POA - Sistema Brasileiro de Inspeção de Produtos de Origem Animal; Suasa - Sistema Unificado de
Atenção à Sanidade Agropecuária. 


\section{Uma análise histórico...}

Tabela 3. Evolucão das legislaç̃es estaduais sobre queijos artesanais brasileiros

\begin{tabular}{|c|c|c|c|}
\hline Estado & Legislação & Principais diretrizes & Referência \\
\hline \multirow[t]{11}{*}{ MG } & Lei 14.185 & $\begin{array}{l}\text { - Dispõe sobre o processo de produção do QMA. } \\
\text { - O QMA confeccionado conforme tradição da área onde for produzido receberá certificação } \\
\text { diferenciada. }\end{array}$ & Minas Gerais (2002b) \\
\hline & $\begin{array}{l}\text { Decreto } \\
42.645\end{array}$ & - Aprova Regulamento da Lei 14.185, de 2002, que dispõe sobre processo de produção do QMA. & Minas Gerais (2002a) \\
\hline & $\begin{array}{l}\text { Decreto } \\
44.864\end{array}$ & $\begin{array}{l}\text { - Altera dispositivos do Regulamento da Lei 14.185, de 2002, aprovado pelo Decreto 42.645, de } \\
2002 .\end{array}$ & Minas Gerais (2008) \\
\hline & Lei 19.492 & $\begin{array}{l}\text { - Altera dispositivos da Lei } 14.185 \text {, de } 2002 . \\
\text { - O art. } 1^{\circ} \text {, o } \S 1^{\circ} \text { do art. } 3^{\circ} \text { e o inciso II do art. } 5^{\circ} \text { da Lei } 14.185 \text {, de } 2002 \text {, passam a vigorar com } \\
\text { a nova redação. }\end{array}$ & Minas Gerais (2011) \\
\hline & Lei 20.549 & - Dispõe sobre a produção e a comercialização do QMA. & Minas Gerais (2012) \\
\hline & Portaria & - Esta portaria aplica-se somente às queijarias integrantes do Sisbi/POA. & Instituto..., (2013) \\
\hline & 1.305 & $\begin{array}{l}\text { Art. } 2^{\circ} \text {. Permite maturação por tempo indicado em pesquisa científica que assegure a qualidade } \\
\text { e inocuidade dos queijos. }\end{array}$ & \\
\hline & Portaria & - Altera a Portaria 1.305, de 2013, acerca do tempo de maturação do QMA. & Instituto..., (2017) \\
\hline & 1.736 & $\begin{array}{l}\text { Art. } 1^{\circ} \text {. Altera o } \S 1^{\circ} \text { do artigo } 2^{\circ} \text { da Portaria } 1.305 \text {, de } 2013 \text { : } \\
\S 1^{\circ} \text { Define: períodos de maturação de, no mínimo, } 14 \text { dias para a microrregião de Araxá, } 17 \\
\text { dias para a microrregião do Serro e } 22 \text { dias paras as microrregiões da Canastra, do Cerrado, do } \\
\text { Campo das Vertentes, da Serra do Salitre e do Triângulo Mineiro, até que sejam realizadas novas } \\
\text { pesquisas. }\end{array}$ & \\
\hline & Lei 23.157 & $\begin{array}{l}\text { - Dispõe sobre a produção e a comercialização do QMA. } \\
\text { - Define o papel do estado, por meio do IMA, na produção e comercialização do QMA. } \\
\text { Art. 20. Fica revogada a Lei } 20.549 \text {, de } 2012 \text {. }\end{array}$ & Minas Gerais (2018) \\
\hline & $\begin{array}{l}\text { Portaria } \\
1.937\end{array}$ & $\begin{array}{l}\text { - Dispõe sobre a habilitação sanitária dos queijos artesanais e da concessão do selo RTE às Arte às } \\
\text { com habilitação sanitária no IMA. }\end{array}$ & Instituto..., (2019) \\
\hline GO & IN 06 & $\begin{array}{l}\text { - Dispõe sobre o processo de fiscalização de produtos alimentícios de origem animal produzidos } \\
\text { de forma artesanal. }\end{array}$ & Goías (2019) \\
\hline \multirow[t]{2}{*}{ MS } & Lei 2.820 & - Dispõe sobre o processo de produção do queijo artesanal caipira. & $\begin{array}{l}\text { Mato Grosso do Sul } \\
\text { (2004) }\end{array}$ \\
\hline & $\begin{array}{l}\text { Portaria } \\
3.532\end{array}$ & - Estabelece normas sobre a produção e a comercialização dos queijos artesanais. & Iagro (2019) \\
\hline $\mathrm{AL}$ & Lei 8.228 & - Dispõe sobre a produção e comercialização de derivados lácteos artesanais. & Alagoas (2020) \\
\hline PB & Lei 11.346 & - Institui o Sistema de Produção e Comercialização de Queijos e Manteigas Artesanais. & Paraíba (2019) \\
\hline \multirow[t]{4}{*}{ PE } & Lei 13.376 & $\begin{array}{l}\text { - Dispõe sobre o processo de produção artesanal do queijo de coalho e de outros produtos } \\
\text { derivados do leite. }\end{array}$ & Pernambuco (2007) \\
\hline & Lei 14.993 & $\begin{array}{l}\text { - Altera a Lei no } 13.376 \text {, de } 20 \text { de dezembro de 2007, que dispõe sobre o processo de produção } \\
\text { do queijo artesanal. }\end{array}$ & Pernambuco (2013) \\
\hline & Lei 16.312 & $\begin{array}{l}\text { - Emenda da Lei 13.376, de 2007. Dispõe sobre a produção artesanal do queijo de coalho e de } \\
\text { outros derivados do leite. }\end{array}$ & Pernambuco (2018) \\
\hline & $\begin{array}{l}\text { Portaria } \\
007\end{array}$ & $\begin{array}{l}\text { - Aprova o Regulamento Técnico de Identidade e Qualidade do Queijo de Coalho Artesanal, } \\
\text { adicionado ou não de condimentos. }\end{array}$ & Agência..., (2018) \\
\hline \multirow[t]{3}{*}{ PA } & Lei 7.565 & $\begin{array}{l}\text { - Dispõe de normas para estabelecimentos de produtos artesanais comestíveis de origem animal } \\
\text { e vegetal. }\end{array}$ & Pará (2011) \\
\hline & $\begin{array}{l}\text { Portaria } \\
418\end{array}$ & $\begin{array}{l}\text { - Aprova o Regulamento Técnico para a Produção do Queijo do Marajó (tipo creme e tipo } \\
\text { manteiga) e define o padrão de identidade e qualidade do queijo do Marajó. }\end{array}$ & Agência..., (2013) \\
\hline & $\begin{array}{l}\text { Portaria } \\
3.671\end{array}$ & - Aprova o Regulamento Técnico de Produção do Queijo Regional de Paragominas. & Agência..., (2014) \\
\hline RO & Lei 4.671 & $\begin{array}{l}\text { - Dispõe sobre a produção e comercialização de queijos artesanais de leite cru e institui o selo } \\
\text { "Queijo Artesanal Rondoniense". }\end{array}$ & Rondônia (2019) \\
\hline \multirow[t]{3}{*}{ RS } & Lei 14.973 & - Dispõe sobre a produção e a comercialização do queijo artesanal serrano. & $\begin{array}{l}\text { Rio Grande do Sul } \\
\text { (2016) }\end{array}$ \\
\hline & $\begin{array}{l}\text { Decreto } \\
54.199\end{array}$ & $\begin{array}{l}\text { - Regulamenta a Lei 14.973, de 2016, que dispõe sobre a produção e a comercialização do queijo } \\
\text { serrano. }\end{array}$ & $\begin{array}{l}\text { Rio Grande do Sul } \\
\text { (2018) }\end{array}$ \\
\hline & IN 10 & - Dispõe sobre a identificação do queijo artesanal serrano. & SEAPDR (2019) \\
\hline \multirow[t]{3}{*}{ RN } & Lei 10.230 & - Dispõe sobre a produção e a comercialização de queijos e de manteigas artesanais. & $\begin{array}{l}\text { Rio Grande do Norte } \\
\text { (2017) }\end{array}$ \\
\hline & $\begin{array}{l}\text { Decreto } \\
27.683\end{array}$ & - Regulamenta a Lei Estadual 10.230, de 2017. & $\begin{array}{l}\text { Rio Grande do Norte } \\
\text { (2018a) }\end{array}$ \\
\hline & $\begin{array}{l}\text { Decreto } \\
28.012\end{array}$ & $\begin{array}{l}\text { - Altera o Decreto Estadual n }{ }^{\circ} 27.683 \text {, de } 26 \text { de janeiro de } 2018 \text {, que regulamentou a Lei Estadual } \\
n^{\circ} 10.230 \text {. }\end{array}$ & $\begin{array}{l}\text { Rio Grande do Norte } \\
\text { (2018b) }\end{array}$ \\
\hline \multirow[t]{3}{*}{$\mathrm{SC}$} & Lei 17.003 & - Dispõe sobre a produção e a comercialização do queijo artesanal serrano. & Santa Catarina (2016) \\
\hline & $\begin{array}{l}\text { Decreto } \\
1.238\end{array}$ & $\begin{array}{l}\text { - Regulamenta a Lei no } 17.003 \text {, de } 2016 \text {, que dispṍe sobre a produção e a comercialização do } \\
\text { queijo artesanal serrano, no estado de Santa Catarina. }\end{array}$ & Santa Catarina (2017) \\
\hline & Lei 17.486 & - Dispõe sobre a produção e a comercialização de queijos artesanais de leite cru. & Santa Catarina (2018) \\
\hline PR & Lei 19.599 & - Dispõe sobre a produção e a comercialização dos queijos artesanais. & Paraná (2018) \\
\hline SE & Lei 8.523 & - Dispõe normas sobre a produção e a comercialização dos queijos artesanais. & Sergipe (2019) \\
\hline
\end{tabular}
Produtos de Origem Animal. 
A aplicação do selo denominado Arte e a designação da fiscalização dos produtos artesanais aos órgãos estaduais de saúde pública, por meio da sanção da Lei 13.680 (Brasil, 2018), proporcionaram maior dinâmica e praticidade à comercialização dos queijos artesanais em nível nacional. O Decreto 9.918 (Brasil, 2019a), que dispõe sobre a fiscalização de produtos de origem animal produzidos de forma artesanal, determinou que esses produtos sejam identificados por um selo único com a indicação "Arte", podendo ser comercializados em todo o território nacional. O decreto estabeleceu que compete aos órgãos de agricultura e pecuária estaduais e distrital conceder o selo Arte e fiscalizar os referidos produtos artesanais, enquanto os produtores devem garantir a qualidade e a inocuidade dos produtos (Brasil, 2019a).

O Mapa, por meio da IN 67 (Brasil, 2019d), estabeleceu os requisitos para que os estados e o Distrito Federal concedam o Selo Arte a alimentos de origem animal produzidos artesanalmente. Caso os requisitos mínimos exigidos não sejam cumpridos, a IN 67 determina o cancelamento do selo Arte e a suspensão da concessão, respectivamente, a produtores e estados que descumprirem a lei. Também foi determinado, mediante a Instrução Normativa $\mathrm{n}^{\circ} 73$ (Brasil, 2019e), o Regulamento Técnico de Boas Práticas Agropecuárias destinadas aos produtores rurais fornecedores de leite para a fabricação de produtos lácteos artesanais, necessário à concessão do selo Arte. Entre outras diretrizes, o regulamento direciona as condições sanitárias do rebanho e estabelece os requisitos higiênico-sanitários mínimos necessários às propriedades rurais para garantia da qualidade do leite.

Embora represente um importante marco para a produção e comercialização de produtos artesanais no Brasil, o sistema de fiscalização dos processos de fabricação desses produtos prevista pelo selo Arte pode ser questionado, uma vez que o Sisbi-POA já contempla essa atividade. Porém, deve-se entender que o selo Arte possui uma ação complementar e conjunta ao SisbiPOA, o que permite uma análise criteriosa dos processos e garante a identidade, qualidade e inocuidade dos queijos artesanais destinados ao consumo humano, minimizando, assim, os riscos à saúde pública. Isso deverá ser assegurado pelos órgãos de agricultura, pecuária e saúde pública estaduais e distrital, que irão conceder o selo Arte, fiscalizar os produtos, estabelecer normas sanitárias e regulamentos complementares, bem como manter o cadastro nacional de produtos artesanais atualizado. Já o Mapa será responsável por estabelecer os procedimentos de verificação da conformidade da concessão do selo Arte, elaborar guias de boas práticas de fabricação, fomentar a educação sanitária, criar o cadastro nacional de produtos artesanais, além de auditar os produtos que obtiveram o selo.

A adesão ao Sisbi-POA também possibilita a comercialização dos produtos artesanais em todo o território nacional; da mesma forma, os órgãos de fiscalização dos estados ou municípios ficam responsáveis pela fiscalização desses produtos. Até fevereiro de 2020, 14 estados brasileiros (Bahia, Espírito Santo, Goiás, Mato Grosso, Maranhão, Mato Grosso do Sul, Minas Gerais, Paraná, Pernambuco, Piauí, Rio Grande do Sul, Rondônia, Santa Catarina, e Tocantins), o Distrito Federal, 23 cidades e quatro consórcios (intermunicipais e interestaduais) aderiram ao Sisbi-POA visando à equivalência dos serviços de inspeção de produtos de origem animal (Brasil, 2019f). Essas adesões evidenciam que os órgãos de fiscalização estaduais e municipais têm explorado a alternativa do Mapa para viabilizar a produção de pequenos produtores, incluindo a produção de queijos artesanais.

Em complementação ao Suasa, a recente publicação do Decreto 10.032 (Brasil, 2019b) regulamenta as competências dos consórcios públicos de municípios no âmbito do Sisbi-POA. Esse decreto prevê que, a partir de fevereiro de 2020, diferentes produtos de origem animal inspecionados por consórcios públicos municipais poderão ser comercializados nos territórios das cidades integrantes desses consórcios, ampliando a abrangência do comércio de alimentos produzidos por pequenos produtores, como queijos artesanais, e representando uma nova alternativa para a expansão do setor. É importante destacar que a obtenção da equivalência está atrelada à comprovação da capacidade dos serviços municipais de avaliar a qualidade e a inocuidade dos produtos com a mesma eficiência do Mapa.

Minas Gerais, o maior produtor de queijo do Brasil (Produção..., 2017), foi o primeiro estado brasileiro a desenvolver uma legislação própria que contemplava a produção de queijo artesanal com leite cru no Brasil, por meio da Lei 14.185 (Minas Gerais, 2002b), regulamentada pelo Decreto 42.645 (Minas Gerais, 2002a) e alterada pelo Decreto 44.864 (Minas Gerais, 2008). Considerando essas normas como modelo, Mato Grosso do Sul foi o segundo estado brasileiro a criar uma legislação própria para regulamentar a produção e o comércio do queijo artesanal caipira (Mato Grosso do Sul, 2004). Atualmente, a Lei Estadual 23.157 (Minas Gerais, 2018) estabelece as diretrizes para a produção e comercialização estadual e interestadual de queijos produzidos com leite cru, por meio da aplicação do selo Arte. Essa lei, que revoga a Lei 20.549 (Minas Gerais, 2012), adequa-se à legislação federal de queijos artesanais, agregando as autorizações de se produzirem variedades dos queijos já existentes, bem como a utilização da etiqueta de caseína, entre outros métodos, aos queijos que não forem embalados.

O período de maturação é uma importante característica de queijos artesanais produzidos com leite cru, uma vez que isso pode interferir diretamente na inocuidade desses produtos. Considerando que as legislações federais passaram a contemplar a redução do período mínimo de maturação, previamente fixado em 60 dias 
(Brasil, 2011, 2013, 2017), estudos científicos começaram a ser desenvolvidos em Minas Gerais, visando certificar qualidade e inocuidade dos queijos artesanais tradicionais quando maturados por períodos inferiores a 60 dias (Dores et al., 2013; Martins 2006; Martins et al., 2015; Sales, 2015). Conforme resultados de alguns desses estudos, a Portaria 1.305 (Instituto..., 2013) definiu em 17 dias o período mínimo de maturação do queijo minas artesanal produzido na microrregião do Serro e mínimo de 22 dias paras as microrregiões da Canastra, do Cerrado, de Araxá e do Campo das Vertentes. Entretanto, a Portaria 1.736 (Instituto..., 2017) permitiu posteriormente a redução para 14 dias do período de maturação do queijo minas artesanal produzido na microrregião de Araxá e definiu o período de 22 dias para maturação dos queijos produzidos nas microrregiões da Serra do Salitre e do Triângulo Mineiro.

A redução do período mínimo de maturação do queijo Araxá ocorreu após um estudo científico que avaliou os padrões microbiológicos e físico-químicos desse produto durante a maturação em diferentes épocas do ano, quando se identificou que o tempo de maturação de 14 dias foi suficiente para que esse produto atingisse os padrões exigidos pela legislação (Sales, 2015).

Recentemente, o Instituto Mineiro de Agropecuária (IMA) publicou a Portaria 1.937, que dispõe sobre a habilitação sanitária dos queijos artesanais e da concessão do selo Arte às queijarias com habilitação sanitária no IMA (Instituto..., 2019). A partir de 2000, o IMA publicou diversas portarias relacionadas à produção de queijos artesanais, que estão disponíveis em seu website oficial (http://www.ima.mg.gov.br/institucional/portarias).

Além de reconhecer oficialmente diversas regiões produtoras, essas portarias serviram para estabelecer normas de defesa sanitária, requisitos básicos das instalações, materiais, equipamentos, condições higiênico-sanitárias e boas práticas na manipulação e fabricação do queijo minas artesanal, bem como alterações nos períodos mínimos de maturação. Assim, o trabalho desenvolvido pelo IMA, em parcerias com outras instituições de Minas Gerais, subsidiou uma série de outras legislações publicadas posteriormente.

No Mato Grosso do Sul (região Centro-Oeste do Brasil), a Agência Estadual de Defesa Sanitária Animal e Vegetal (Iagro) publicou recentemente a Portaria 3.632 (Agência..., 2019), que estabelece normas sobre a produção e a comercialização dos queijos artesanais no estado. A portaria complementa a Lei 2.820 (Mato Grosso do Sul, 2004), que trata apenas do queijo artesanal caipira. Além disso, a Agência Goiana de Defesa Agropecuária (Agrodefesa), por meio da Instrução Normativa 06 (Goías..., 2019), também normatizou a produção e comercialização de queijos artesanais em Goiás.
A região Sul do Brasil apresenta, em todos os seus estados, legislações específicas que viabilizam a produção e comercialização de queijos artesanais (Tab. 3). No Paraná, a Lei 19.599 (Paraná, 2018) enfatiza a utilização de leite cru bovino da própria propriedade rural para a produção de queijos tradicionais, assim como ocorre no Rio Grande do Sul, pela Lei 14.973 (Rio Grande do Sul, 2016), regulamentada pelo Decreto 54.199 (Rio Grande do Sul, 2018) e específica em relação à produção e comercialização do queijo serrano. A Secretaria da Agricultura, Pecuária e Desenvolvimento Rural (SEAPDR) do Rio Grande do Sul ainda publicou a Instrução Normativa 10 (Rio Grande do Sul, 2019), que dispõe sobre a identificação do queijo artesanal serrano.

Já em Santa Catarina, a legislação abrange a utilização de leite cru bovino para a produção de queijos artesanais, permitindo sua obtenção em propriedades próximas à queijaria, pela Lei 17.486 (Santa Catarina, 2018). O estado também possui uma legislação específica para o queijo artesanal serrano (Santa Catarina, 2016, 2017), que determina período mínimo de maturacão de 60 dias. No entanto, legislações de outros estados da região Sul não determinam os períodos de maturação para os queijos produzidos com leite cru; nessas situações, entende-se que o período mínimo de 60 dias deve ser respeitado, considerando o que é determinado pela legislação federal (Brasil, 2017).

Atualmente, cinco estados da região Nordeste (Alagoas, Paraíba, Pernambuco, Rio Grande do Norte e Sergipe) possuem legislações que regulamentam a produção e comercialização de queijos e de outros derivados lácteos artesanais (Tab. 3): Lei 8.228 (Alagoas, 2020), Lei 10.230 (Rio Grande do Norte, 2017), Lei 11.346 (Paraíba, 2019), Lei 13.376 (Pernambuco, 2007), alterada pela Lei 16.312 (Pernambuco, 2018), e Lei 8.523 (Sergipe, 2019). Em relação aos queijos de coalho e manteiga, produtos tradicionais na região Nordeste, as orientações técnicas descritas na Instrução Normativa 30 (Brasil, 2001) indicam que o cozimento da massa do queijo de coalho é uma etapa opcional. A norma ainda determina que o leite seja submetido à pasteurização ou ao tratamento térmico equivalente e indica que o queijo de coalho é um produto comercializado normalmente com até 10 dias após a produção; em relação ao queijo manteiga, sua massa deve ser submetida a tratamento térmico e passa por processo de fusão, não há especificação do período de comercialização (Brasil, 2001). Já a Portaria 07, publicada pela Agência de Defesa e Fiscalização Agropecuária do estado de Pernambuco (Agência..., 2018), que estabelece o Regulamento Técnico de Identidade e Qualidade do Queijo de Coalho Artesanal, define esse produto como aquele obtido por coagulação do leite cru, podendo ser fresco ou maturado e/ou defumado. Quando maturado, a Portaria 07 indica período mínimo de 60 dias. 
Rondônia, localizado na região Norte do Brasil, também passou a legislar sobre a produção e comercialização de queijos artesanais de leite cru e instituiu o selo "Queijo Artesanal Rondoniense", por meio da Lei 4.671 (Rondônia, 2019). No Pará, a Portaria 418 (Agência..., 2013) determinou as diretrizes para a produção do queijo do Marajó, produzido com leite cru bubalino ou mistura deste com até $40 \%$ de leite cru bovino, exclusivamente, na Ilha de Marajó, amparada na Lei Estadual de produtos artesanais 7.565 (Pará, 2011). Esse queijo deve ser submetido a um processo térmico de cozimento da massa (Agência..., 2013; Brasil, 2017), e a legislação determina o comércio do queijo do Marajó em até sete a 30 dias, dependendo do modo de embalagem e da temperatura de armazenamento; prazos maiores podem ser analisados pelo órgão fiscalizador e aceitos mediante estudos de comprovação técnica favorável. Ainda, a Portaria 3.671 estabeleceu o Regulamento Técnico de Produção do Queijo Regional de Paragominas, o qual também passa por processo de filagem da massa (Agência..., 2014).

Outros queijos artesanais que passam por processos de cozimento ou filagem da massa, teoricamente, constituem produtos prontos para o consumo. No entanto, queijos como o cabacinha e köchkase ainda não dispõem de legislações específicas que estabeleçam, por exemplo, prazo de validade ou condições de armazenamento desses produtos. O queijo cabacinha e o queijo tipo parmesão de Alagoa (anteriormente denominado como tipo parmesão da Mantiqueira) podem ser considerados como variedades dos queijos produzidos artesanalmente em Minas Gerais. Entretanto, as etapas de cozimento/filagem e de maturação prolongada, bem como diferenças em processos tecnológicos e em fatores edafoclimáticos, conferem características sensoriais distintas nessas variedades e nos demais queijos artesanais produzidos em Minas Gerais (Igência..., 2014b, a; Pinto et al., 2015; Santos Filho et al., 2016).

Em paralelo aos esforços estaduais para regulamentação de produtos artesanais, a criação do selo Arte, por meio da Lei 13.680 (Brasil, 2018), representa um marco que visa estimular e regulamentar a produção e comercialização desses produtos. Devido à regulamentação dessa lei, os estados brasileiros tendem a definir regulamentos próprios para a viabilização da produção de alimentos artesanais. Como consequência, a determinação de Indicações Geográficas, contempladas pela Lei de Propriedade Industrial (Brasil, 1996b), também tem despertado o interesse de produtores e associações de produtores de queijos artesanais, pois essas indicações remetem ao reconhecimento de determinado país, estado, município ou mesmo região que apresenta características típicas de produção. No Brasil, essas indicações são classificadas em Indicação de Procedência (IP) e Denominação de Origem (DO). IP se refere à localidade geográfica que se tornou tradicionalmente conhecida em virtude da produção ou extração de um produto, ou ainda pela prestação de serviço, e DO se refere à região geográfica que apresenta fatores peculiares naturais e humanos, determinantes das características de um produto ou serviço (Brasil, 1996b; Instituto..., 2019).

A atuação do Mapa no processo de concessão de IG de produtos agropecuários foi oficializada por meio da criação da Coordenação de Incentivo à Indicação Geográfica de Produtos Agropecuários (CIG), em 2005. A partir de então, o Mapa passou a ter um papel fundamental no planejamento, na divulgação, na coordenação e na avaliação do desenvolvimento de atividades relacionadas a concessões de IG de produtos agropecuários (Santiago et al., 2019). Treinamentos técnicos a profissionais do Mapa e de outras instituições foram promovidos devido à criação da CIG, com o objetivo de padronizar a metodologia de trabalho dos agentes envolvidos. Assim, um Comitê de Trabalho foi instituído em 2012 para a elaboração de procedimentos padronizados e implementação dos Processos de Trabalho sobre Signos Distintivos (IG e Marcas Coletivas). $\mathrm{Na}$ prática, isso resultou no desenvolvimento e na publicação de metodologias de trabalho voltadas para identificar ativos territoriais, sensibilizar e capacitar os produtores rurais, traçar o panorama de produção regional e fortalecer a cadeia produtiva local (Santiago et al., 2019). Após anos de trabalho, os técnicos desenvolveram o Mapa Interativo - Signos Distintivos Registrados e Produtos Potenciais, publicado em 2018 (Brasil, 2019c; Santiago et al., 2019).

A formalização de parcerias institucionais tem sido crucial para ampliar o fomento à implementação de IG, pois cada instituição contribui com sua expertise e fortalece as redes de discussões, que fundamentalmente servem de base para a identificação de regiões e da construção do perfil de IG no Brasil. Esse trabalho multidisciplinar envolve instituições das esferas federal, estadual e municipal, incluindo diferentes ministérios, empresas e órgãos de pesquisa, ciência, tecnologia, extensão e conservação, universidades e outras instituições de ensino, bem como secretarias e órgãos de agricultura estaduais e municipais, cooperativas e associações de produtores, entre outros (Maiorki e Dallabrida, 2015; Santiago et al., 2019). Além disso, o acordo franco-brasileiro de cooperação técnica, assinado em 2011, foi um importante marco para o desenvolvimento do setor de produção de alimentos artesanais no Brasil. O intercâmbio de conhecimentos das IG foi o ponto inicial desse acordo, em que foram abordados temas relacionados aos regulamentos franceses e da União Europeia sobre IG, marcas de qualidade, e normas higiênico-sanitária de produtos agropecuários (Santiago et al., 2019).

O consentimento da IG determina um destaque a um produto ou serviço em relação a sua qualidade e 
especificidade, designadas por sua região de origem. O reconhecimento da identidade de um produto está ligado à preservação de suas características tradicionais, o que agrega valores econômico-culturais e desenvolvimento regional (Maiorki e Dallabrida, 2015). Apesar de todas as ações realizadas pelo Mapa e por instituições parceiras, até o momento apenas dois queijos produzidos em Minas Gerais (minas artesanal do Serro e da Canastra) e o queijo colonial da Colônia de Witmarsum (Paraná) têm reconhecimento de IG por IP pelo Instituto Nacional de Propriedade Industrial (Instituto..., 2019). A Cooperativa Agroindustrial Witmarsum foi a primeira indústria de laticínios que produz sob o SIF a receber uma certificação de IG concedida pelo Inpi. Assim, o selo de IG poderá ser indicado nos rótulos dos queijos 'colonial' e 'colonial com pimenta verde', atestando a procedência deles como "queijo da colônia Witmarsum".

Atualmente existe um processo organizacional em distintas regiões brasileiras, produtoras de queijos artesanais, para a obtenção do selo de IG. De acordo com Cruz e Hespanhol (2018), já foram identificadas no Brasil 16 regiões produtoras de queijos artesanais produzidos com leite cru. Excetuando-se os produtos/regiões que já possuem o selo de IG, outras sete regiões possuem projetos de IG em desenvolvimento, que visam contemplar os seguintes queijos: minas Serra do Salitre (MG), minas Araxá (MG), Marajó (PA), coalho do Agreste (PE), manteiga do Seridó (RN), coalho do Jaguaribe (CE) e serrano (RS e SC).

Desde a sanção do Riispoa, em 1950 (Brasil, 1950), as determinações de períodos mínimos de maturação, os critérios microbiológicos, a criação do Sisbi-POA e, mais recentemente, o avanço na questão de IG, bem como a criação e regulamentação do selo Arte, trouxeram as mais importantes normatizações relacionadas à produção e comercialização de queijos no Brasil. Os estados brasileiros, em especial Minas Gerais, têm assumido um importante papel direcionador da produção e comercialização de queijos artesanais. Por meio da articulação entre diferentes instituições estaduais, como Instituto Mineiro de Agropecuária (IMA), Empresa de Assistência Técnica e Extensão Rural do Estado de Minas Gerais (EmaterMG), universidades e outras organizações, Minas Gerais tem obtido êxito no que diz respeito à caracterização e regulamentação do comércio das diversas variedades de queijos artesanais produzidos no estado.

Fundamentalmente, além da manutenção das tradições locais, a inocuidade dos queijos artesanais tem sido considerada como principal fator determinante para regulamentação. Estudos detalhados são essenciais para subsidiar o desenvolvimento de legislações relacionadas à produção e comercialização desses queijos. Considerando o risco sanitário, as legislações em vigência (Brasil 2018, 2019) atribuem aos órgãos de inspeção e fiscalização a função de fornecer orientações técnicas para os pequenos produtores. No entanto, é importante destacar que as agências de assistência técnica e extensão rural, associações e/ou cooperativas possuem papel fundamental para o treinamento técnico de produtores rurais, visando à orientação sobre manejo sanitário do rebanho, a boas práticas de obtenção de leite cru, à produção de queijos, à adoção de planos de autocontrole, a medidas preventivas e corretivas, para evitar que micro-organismos patogênicos ou agentes deteriorantes comprometam a qualidade e inocuidade dos produtos finais. Assim, a função dos órgãos de inspeção e fiscalização deve estar centrada no risco sanitário.

Em relação a orientações técnicas, a União Europeia publicou recentemente o "Guia Europeu para Boas Práticas de Higiene na Produção de Queijo Artesanal e Produtos Lácteos", que tem como público-alvo os produtores rurais (EU, 2016). Esse guia é de utilização facultativa e representa um esforço da União Europeia em desenvolver a consciência e preocupação do produtor rural sobre aspectos de qualidade e inocuidade do leite cru destinado à produção de alimentos artesanais direcionados ao consumo humano. $\mathrm{O}$ guia traz conceitos básicos de boas práticas de produção e de manipulação de alimentos, conceitos de programas de Análises de Perigos e Pontos Críticos de Controle (APPCC), autocontrole, rastreabilidade, análises de riscos e defeitos tecnológicos observados em diferentes produtos lácteos artesanais (European..., 2016).

A adesão dos estados junto ao Sisbi-POA já vinha viabilizando a comercialização interestadual dos queijos artesanais produzidos no Brasil, contanto que as legislações estaduais se adequem a diretrizes preestabelecidas pelo Sisbi-POA (Brasil, 2006, 2010). Com a publicação e regulamentação da Lei do Selo Arte (Brasil, 2018; 2019a), foi concedido o livre comércio interestadual de produtos artesanais, desde que houvesse fiscalização dos produtos artesanais que tenham obtido o selo. Assim, o comércio de queijos artesanais brasileiros passou a ser viabilizado nas últimas décadas por meio da regulamentação de leis específicas sequencialmente elaboradas e publicadas, visando ao desenvolvimento desse setor.

A implementação de novas normas é algo natural, porém deve haver um amplo debate antes de sua aprovação, sempre subsidiado por dados científicos. Por exemplo, quando ocorre a caracterização de regiões produtoras, os estudos devem tipificar os produtos adequadamente, estabelecer critérios de identidade, qualidade e inocuidade. No entanto, ainda não foram definidos quais critérios esses estudos científicos devem contemplar, como metodologias e procedimentos. Fatalmente, essas constantes atualizações podem gerar inconsistências e contradições pontuais entre as normas em vigência, o 
que deve ser identificado e corrigido. Na opinião dos autores, a organização dos produtores em associações ou cooperativas tem se mostrado uma alternativa pertinente para viabilizar treinamentos voltados principalmente para cuidados higiênicos sanitários e implementação de IG (questões que ainda precisam ser aprimoradas e desenvolvidas no Brasil) e proporcionar a efetiva fiscalização para que os parâmetros determinados pelas legislações sejam verificados.

\section{AGRADECIMENTOS}

Os autores agradecem o suporte financeiro do Conselho Nacional de Desenvolvimento Científico e Tecnológico (CNPq), da Coordenação de Aperfeiçoamento de Pessoal de Nível Superior (Capes) e da Fundação de Amparo à Pesquisa do Estado de Minas Gerais (Fapemig).

\section{REFERÊNCIAS}

AGÊNCIA de Defesa e Fiscalização Agropecuária do Estado de Pernambuco. Portaria n ${ }^{\circ} 007$, de 04 de janeiro de 2018. Aprova o regulamento técnico de identidade e qualidade do queijo de coalho no Estado de Pernambuco, adicionado ou não de condimentos. Recife, 04 de janeiro de 2018. Disponível em: $<$ http://www2.adagro.pe.gov.br/web/adagro/legisla cao?p_p_id=110_INSTANCE_Jdj2\&p_p_lifecycle $=0$ \&p_p_state $=$ maximized $\&$ p_p_mode $=$ view $\& \_110 \_I N S$ TANCE_Jdj2_struts_action=\%2Fdocument_library_di splay\%2Fview\&_110_INSTANCE_Jdj2_folderId=19 9865>. Acessado em 22 fev. 2020.

AGÊNCIA Estadual de Defesa Agropecuária do Estado do Pará Portaria $n^{\circ}$ 481, de 26 de fevereiro de 2013. Aprova o regulamento técnico de produção do Queijo do Marajó e dá outras providências. Diário Oficial do Estado do Pará, Belém, 7 de mar. 2013.

AGÊNCIA Estadual de Defesa Agropecuária do Estado do Pará. Portaria n ${ }^{\circ} 3.671$, de 30 de setembro de 2014. Aprova o regulamento técnico de produção do queijo regional de Paragominas e dá outras providências. Diário Oficial do Estado do Pará, Belém, 1 out. 2014.

AGÊNCIA Estadual de Defesa Sanitária Animal e Vegetal. Portaria ${ }^{\circ}$ 3.632, de 19 de novembro de 2019. Estabelece Normas sobre a produção e a comercialização dos queijos artesanais no Estado de Mato Grosso do Sul e dá outras providências. Diário Oficial do Estado de Mato Grosso do Sul, Campo Grande, 22 nov. 2019.

ALAGOAS. Lei $\mathrm{n}^{\circ}$ 8.228, de 07 de janeiro de 2020. Dispõe sobre a produção e comercialização de derivados lácteos artesanais produzidos no estado de Alagoas. Diário Oficial do Estado de Alagoas, Maceió, 8 jan. 2020.

BATTAGLINI, P.P.; FAGNARI, R.. Legislação brasileira de leite e derivados. Londrina: Unopar, 2014. cap.1, p.11-28.
BEMFEITO, R.M.; RODRIGUES, J.F.; SILVA, J.G.; ABREU, L.R. Temporal dominance of sensations sensory profile and drivers of liking of artisanal Minas cheese produced in the region of Serra da Canastra, Brazil. J. Dairy Sci., v.99, p.7886-7897, 2016.

BORELLI, B.M.; LACERDA, I.C.A.; PENIDO, F.C.L.; ROSA A.C. Traditional Cheeses Produced in Brazil: Characterisation, Production Technologies and Health Implications. In: PERKINS, E. (Ed.). Food microbiology fundamentals, challenges and health implications. New York: Nova Science Publishers, Inc., 2016. cap.7, p.161-189.

BRANDÃO, A.F; MELLO, J.A.G.; SILVA, L.D. Diálogos das grandezas do Brasil. Rio de Janeiro: Dois Mundos, 1943.

BRASIL. Ministério da Agricultura, Pecuária e Abastecimento. Instrução Normativa $\mathrm{n}^{\circ} 30$, de 07 de agosto de 2013. Revoga a Instrução Normativa $n^{\circ} 57$. Diário Oficial da União, Brasília, 8 ago. 2013. Seção 1, p.19.

BRASIL. Ministério da Agricultura, Pecuária e Abastecimento. Instrução Normativa ${ }^{\circ}$ 67, de 10 de dezembro de 2019. Estabelece os requisitos para que os Estados e o Distrito Federal realizem a concessão do Selo Arte, aos produtos alimentícios de origem animal produzidos de forma artesanal. Diário Oficial da União, Brasília, 11 dez. 2019d. Seção 1, p.34.

BRASIL. Ministério da Agricultura, Pecuária e Abastecimento. Instrução Normativa $\mathrm{n}^{\circ} 73$, de 23 de dezembro de 2019. Estabelecer, em todo o território nacional, o Regulamento Técnico de Boas Práticas Agropecuárias destinadas aos produtores rurais fornecedores de leite para a fabricação de produtos lácteos artesanais, necessárias à concessão do selo ARTE. Diário Oficial da União, Brasília, 30 dez. 2019e.

BRASIL. Ministério da Agricultura, Pecuária e Abastecimento. Decreto $n^{\circ} 30.691$, de 29 de março de 1952. Aprova o novo regulamento da inspeção industrial e sanitária de produtos de origem animal RIISPOA. Diário Oficial dos Estados Unidos do Brasil, Rio de Janeiro, 7 jul. 1952.

BRASIL. Ministério da Agricultura, Pecuária e Abastecimento. Decreto $\mathrm{n}^{\circ} 1.255$, de 25 de junho de 1962. Altera o Decreto $\mathrm{n}^{\circ} 30.691$, de 29 de março de 1952, que aprovou o regulamento da inspeção industrial e sanitária de produtos de origem animal. Diário Oficial dos Estados Unidos do Brasil, Brasília, 4 jul. 1962.

BRASIL. Ministério da Agricultura, Pecuária e Abastecimento. Decreto $n^{\circ} 9.013$, de 29 de março de 2017. Regulamenta a Lei $n^{\circ} 1.283$, de 18 de dezembro de 1950 , e a Lei $n^{\circ} 7.889$, de 23 de novembro de 1989 , que dispõem sobre a inspeção industrial e sanitária de produtos de origem animal. Diário Oficial União, Brasília, 30 mar. 2017. 
BRASIL. Ministério da Agricultura, Pecuária e Abastecimento. Decreto ${ }^{\circ}$ 9.918, de 18 de julho de 2019. Regulamenta o art. 10-A da Lei $\mathrm{n}^{\circ} 1.283$, de 18 de dezembro de 1950, que dispõe sobre o processo de fiscalização de produtos alimentícios de origem animal produzidos de forma artesanal. Diário Oficial da União, Brasília, 19 jul. 2019a.

BRASIL. Ministério da Agricultura, Pecuária e Abastecimento. Decreto $\mathrm{n}^{\circ} 10.032$, de 1 de outubro de 2019. Altera o Anexo ao Decreto $n^{\circ} 5.741$, de 30 de março de 2006, para dispor sobre as competências dos consórcios públicos de Município no âmbito do Sistema Brasileiro de Inspeção de Produtos de Origem Animal. Diário Oficial da União, Brasília, 2 out. 2019b.

BRASIL. Ministério da Agricultura, Pecuária e Abastecimento. Instrução Normativa $n^{\circ} 30$, de 26 de junho de 2001. Aprova os regulamentos técnicos de identidade e qualidade de manteiga da terra ou manteiga de garrafa; queijo de Coalho e queijo de Manteiga. Diário Oficial da União, Brasília, 16 jul. 2001.

BRASIL. Ministério da Agricultura, Pecuária e Abastecimento. Instrução Normativa $\mathrm{n}^{\circ}$ 57, de 15 de dezembro de 2011. Dispõe sobre o período de maturação dos queijos artesanais tradicionalmente elaborados a partir de leite cru. Diário Oficial da União, Brasília, 16 dez. 2011.

BRASIL. Ministério da Agricultura, Pecuária e Abastecimento. Lei ${ }^{\circ} 1.283$, de 18 de dezembro de 1950. Dispõe sobre a inspeção sanitária e industrial dos produtos de origem animal, e dá outras providências. Diário Oficial dos Estados Unidos do Brasil, Rio de Janeiro, 19 dez. 1950.

BRASIL. Ministério da Agricultura, Pecuária e Abastecimento. Lei ${ }^{\circ} 7.889$, de 23 de novembro de 1989. Dispõe sobre a Inspeção Sanitária e Industrial de Produtos de Origem Animal. Diário Oficial da União, Brasília, 24 nov. 1989.

BRASIL. Ministério da Agricultura, Pecuária e Abastecimento. Lei n ${ }^{\circ} 8.171$, de 17 de janeiro de 1991. Dispõe sobre a política agrícola. Diário Oficial da União, Brasília, 18 jan. 1991.

BRASIL. Ministério da Agricultura, Pecuária e Abastecimento. Lei $\mathrm{n}^{\circ}$ 9.712, de 20 de novembro de 1998. Altera a Lei no 8.171, de 17 de janeiro de 1991, acrescentando-lhe dispositivos referentes à defesa agropecuária. Diário Oficial da União, Brasília, 23 nov. 1998.

BRASIL. Ministério da Agricultura, Pecuária e Abastecimento. Lei n ${ }^{\circ} 13.680$, de 14 de junho de 2018. Altera a Lei $n^{\circ} 1.283$, de 18 de dezembro de 1950, para dispor sobre o processo de fiscalização de produtos alimentícios de origem animal produzidos de forma artesanal. Diário Oficial da União, Brasília, 15 jun. 2018. Seção 1, p.2.
BRASIL. Ministério da Agricultura, Pecuária e Abastecimento. Mapa Interativo - Signos Distintivos Registrados e Produtos Potenciais. Brasília, 2019c. Disponível em: <http://www.agricultura.gov.br/ assuntos/sustentabilidade/indicacao-geografica/mapainterativo>. Acessado em: 18 ago. 2019c.

BRASIL. Ministério da Agricultura, Pecuária e Abastecimento. Portaria $n^{\circ} 146$, de 07 de março de 1996. Aprova os Regulamentos Técnicos de Identidade e Qualidade de Produtos Lácteos. Diário Oficial da União, Brasília, 11 mar. 1996a.

BRASIL. Ministério da Agricultura, Pecuária e Abastecimento. Resolução n ${ }^{\circ}$ 07, de 28 de novembro de 2000. Critérios de funcionamento e de controle da produção de queijarias, para seu relacionamento junto ao serviço de inspeção federal. Diário Oficial da União, Brasília, 2 jan. 2001.

BRASIL. Ministério da Agricultura, Pecuária e Abastecimento. Sistema Brasileiro de Inspeção de Produtos de Origem Animal - SISBI-POA. 2019f. Disponível em <http://www.agricultura.gov.br/assuntos/inspecao/pro dutos-animal/sisbi-1>. Acessado em: 18 ago. 2019f.

BRASIL. Ministério do Desenvolvimento, Indústria e Comércio Exterior. Lei $\mathrm{n}^{\circ}$ 9.279, de 14 de maio de 1996. Regula direitos e obrigações relativos à propriedade industrial. Diário Oficial da União, Brasília, 15 maio 1996b.

BRASIL. Sistema Unificado de Atenção à Sanidade Agropecuária. Decreto $\mathrm{n}^{\circ} 5.741$, de 30 de março de 2006. Regulamenta os arts. 27-A, 28-A e 29-A da Lei $\mathrm{N}^{\circ} 8.171$, de 17 de janeiro de 1991, organiza o Sistema Unificado de Atenção à Sanidade Agropecuária, e dá outras providências. Diário Oficial da União, Brasília, 31 mar. 2006. Seção 1, p.82.

BRASIL. Sistema Unificado de Atenção à Sanidade Agropecuária. Decreto $\mathrm{n}^{\circ} 7.216$, de 17 de junho de 2010. Dá nova redação e acresce dispositivos ao Regulamento dos arts. 27-A, 28-A e 29-A da Lei ${ }^{\circ}$ 8.171, de 17 de janeiro de 1991, aprovado pelo Decreto $\mathrm{n}^{\circ}$ 5.741, de 30 de março de 2006, e dá outras providências. Diário Oficial da União, Brasília, 18 jun. 2010. Seção 1, p.2.

CASTRO, R.D.; OLIVEIRA, L.G.; SANT'ANNA, F.M. et al. Lactic acid microbiota identification in water, raw milk, endogenous starter culture, and fresh Minas artisanal cheese from the Campo das Vertentes region of Brazil during the dry and rainy seasons. $J$. Dairy Sci., v.99, p.6086-6096, 2016.

CRUZ, B.E.V.; HESPANHOL, R.A.M. Indicação geográfica e queijos artesanais: marco legal e desafios a uma política para este segmento no Brasil. Confins, v.37, n.7, 2018. 
CRUZ, F.T.; MENASCHE, R. O debate em torno de queijos feitos de leite cru: entre aspectos normativos e a valorização da produção tradicional. Visa Debate Soc. Ciênc. Tecnol., v.2, p.34-42, 2014.

DIAS, J.C. Uma longa e deliciosa viagem: o primeiro livro da história do queijo no Brasil. [s.1.]: Barleus, 2010. 4p.

DORES, M.T.; FERREIRA, C.L.L.F. Queijo minas artesanal, tradição centenária: ameaças e desafios. Rev. Bras. Agropecu. Sustentável, v.2, p.26-34, 2012.

DORES, M.T.; NOBREGA, J.E.; FERREIRA, C.L.L.F. Room temperature aging to guarantee microbiological safety of Brazilian artisan Canastra cheese. Food Sci. Technol., v.33, p.180-185, 2013.

EUROPEAN Union. European guide for good hygiene practices in the production of artisanal cheese and dairy products. Europe: FACEnetwork, 2016. 98p.

FAVA, L.W.; MORAES H.J.F.; PINTO, A.T.; SCHMIDT, V. et al. Characteristics of colonial handmade cheeses sold in an agricultural show. Acta Sci. Vet., v.40, p.1-6 2012.

GOIÁS. Agência Goiana de Defesa Agropecuária. Instrução Normativa n ${ }^{\circ}$ 06, de 20 de dezembro de 2019. Dispõe sobre o processo de fiscalização de produtos alimentícios de origem animal produzidos de forma artesanal. Diário Oficial do Estado de Goiás, Goiânia, 27 dez. 2019.

GRAÇA P.; GREGÓRIO M.J. Evolução da política alimentar e de nutrição em Portugal e suas relações com o contexto internacional. Rev. Alimentação Humana. v.18, p.79-96, 2012.

GRIECO, J.M. The maastricht treaty, economic and monetary union and the neo-realist research programme. Rev. Int. Stud., v.21, p.21-40, 1995.

INSTITUTO do Patrimônio Histórico e Artístico Nacional. Dossiê interpretativo do modo artesanal de fazer queijo de Minas: Serro, Serra da Canastra e Serra do Salitre (Alto Paranaíba). Brasília, DF: Iphan, 2014, 140p.

INSTITUTO do Patrimônio Histórico e Artístico Nacional. Modo artesanal de fazer Queijo de Minas. Registro dos queijos artesanais de Minas Gerais, nas regiões do Serro, da Serra da Canastra e Salitre/Alto Paraíba. Processo n o01450.012192/2006-65. Belo Horizonte, 2008.

INSTITUTO Mineiro Agropecuário. Portaria n $\mathrm{n}^{\circ}$ 1.453, de 01 de dezembro de 2014. Identifica a região de Alagoa como produtora de queijo tipo parmesão no modo artesanal. Diário Oficial do Estado de Minas Gerais, Belo Horizonte, 1 dez. 2014a.

INSTITUTO Mineiro Agropecuário. Portaria n 1403 , de 02 de maio 2014. Identifica a região do Vale do Jequitinhonha como produtora de queijo cabacinha. Diário Oficial do Estado de Minas Gerais, Belo Horizonte, 10 maio 2014b.
INSTITUTO Mineiro de Agropecuária. Portaria IMA $\mathrm{n}^{\circ} 1.736$, de 27 de julho de 2017. Altera a Portaria $\mathrm{n}^{\circ}$ 1.305/2013, de 30 de abril de 2013, que dispõe sobre o período de maturação do Queijo Minas Artesanal. Diário Oficial do Estado de Minas Gerais, Belo Horizonte, 28 jul. 2017.

INSTITUTO Mineiro de Agropecuária. Portaria $n^{\circ}$ 1.305, de 30 de abril de 2013. Estabelece diretrizes para produção de queijo minas artesanal exclusivamente a partir de leite cru de vaca, de produção própria, com utilização de soro fermento (pingo), em regiões específicas do estado de Minas Gerais. Diário Oficial do Estado de Minas Gerais, Belo Horizonte, 1 maio 2013.

INSTITUTO Mineiro de Agropecuária. Portaria $\mathrm{n}^{\circ}$ 1.937, de 14 de agosto de 2019. Dispõe sobre a habilitação sanitária dos queijos artesanais e da concessão do selo Arte às queijarias com habilitação sanitária no IMA. Instituto Mineiro de Agropecuária, Belo Horizonte, 14 ago. 2019a.

INSTITUTO Nacional Do Patrimônio Industrial. Guia básico de Indicação Geográfica. 2019. Disponível em: <http://www.inpi.gov.br/menu-servicos/indicacaogeografica/guia-basico-de-indicacao-geografica> Acessado em: 22 out. 2019b.

KAMIMURA, B.A.; MAGNANI, M.; LUCIANO, W.A. et al. Brazilian artisanal cheeses: an overview of their characteristics, main types and regulatory aspects. Compr. Rev. Food Sci. Food Saf., v.18, p.1636-1657, 2019.

LIMA, C.D.L.C.; CERQUEIRA, M.O.P.; FERREIRA, E.G. et al. Microbiological, physical-chemical and sensory evaluation of a traditional Brazilian cheese during the ripening process. World J. Microbiol. Biot., v.24, p.2389-2395, 2008.

LIMA, M.C.; CONCEIÇÃO, M.L.; SCHAFFNER, D.W.; SOUZA, E.L. Intrinsic parameters and bacterial growth prediction in a brazilian minimally ripened cheese (Coalho) during refrigerated storage. J. Food Prot., v.81, p.1800-1809, 2018.

MACHADO, E.C.; FERREIRA, C.L.L.F.; FONSECA, L.M. et al. Características físico-químicas e sensoriais do queijo Minas artesanal produzido na região do Serro, Minas Gerais. Food Sci. Technol., v.24, p.516-521, 2004.

MAIORKI, G.J.; DALLABRIDA, V.R. A indicação geográfica de produtos: um estudo sobre sua contribuição econômica no desenvolvimento territorial. Interações, v.16, p.13-25, 2015.

MARTINS, J.M. Características físico-químicas $e$ microbiológicas durante a maturação do queijo minas artesanal da região do Serro. 2006. 158f. 2006. Tese (Doutorado em Ciência e Tecnologia de Alimentos) Universidade Federal de Viçosa, Viçosa, MG. 
MARTINS， J.M.; GALINARI, E.; PIMENTELFILHO, N.J. et al. Determining the minimum ripening time of artisanal Minas cheese, a traditional Brazilian cheese. Braz. J. Microbiol., v.46, p.219-230, 2015.

MATO GROSSO DO SUL. Lei ${ }^{\circ} 2.820$ de 04 de maio de 2004. Dispõe sobre o processo de produção do Queijo Artesanal Caipira, e dá outras providências. Diário Oficial do Estado de Mato Grasso do Sul, Campo Grande, 5 maio 2004.

MENESES, J.N.C. Modos de fazer e a materialidade da cultura "imaterial": o caso do queijo artesanal de Minas Gerais. Patrimônio e Memória, v.5, p.19-33, 2007.

MENESES, J.N.C. Queijo Artesanal de Minas. Patrimônio Cultural do Brasil. Dossiê interpretativo, 2006. v.1, 156p.

MERGAREGO NETTO, M. A geografia do queijo minas artesanal. 2011. 420f. Tese (Doutorado) Universidade Estadual Paulista, Instituto de Geociências e Ciências Exatas, Rio Claro, SP.

MINAS GERAIS. Decreto n ${ }^{\circ} 42.645$ de 05 de junho de 2002. Aprova o Regulamento da Lei $n^{\circ} 14.185$, de 31 janeiro de 2002, que ispõe sobre o processo de produção de Queijo Minas Artesanal. Diário Oficial do Estado de Minas Gerais, Belo Horizonte, 6 jun. 2002a.

MINAS GERAIS. Decreto ${ }^{\circ} 44.864$ de 01 de agosto de 2008. Altera o Regulamento da Lei $n^{\circ} 14.185$, de 31 de janeiro de 2002, que dispõe sobre o processo de produção de Queijo Minas Artesanal. Diário Oficial do Estado de Minas Gerais, Belo Horizonte, 2 ago. 2008.

MINAS GERAIS. Lei $\mathrm{n}^{\circ} 14.185$ de 31 de janeiro de 2002. Dispõe sobre o processo de produção do Queijo Minas Artesanal e dá outras providências. Diário Oficial do Estado de Minas Gerais, Belo Horizonte, 1 fev. 2002b.

MINAS GERAIS. Lei $n^{\circ} 19.492$ de 13 de janeiro de 2011. Altera dispositivos da Lei $\mathrm{n}^{\circ} 14.185$, de 31 de janeiro de 2002, que dispõe sobre o processo de produção do Queijo Minas Artesanal e dá outras providências. Diário Oficial do Estado de Minas Gerais, Belo Horizonte, 14 jan. 2011.

MINAS GERAIS. Lei $\mathrm{n}^{\circ} 20.549$, de 18 de dezembro de 2012. Dispõe sobre a produção e a comercialização dos queijos Artesanais de Minas Gerais. Diário Oficial do Estado de Minas Gerais, Belo Horizonte, 19 dez. 2012.

MINAS GERAIS. Lei $\mathrm{n}^{\circ} 23.157$, de 18 de dezembro de 2018. Dispõe sobre a produção e a comercialização dos queijos artesanais de Minas Gerais. Diário Oficial do Estado de Minas Gerais, Belo Horizonte, 19 dez. 2018.

PARÁ. Lei no 7.565, de 25 de setembro de 2011. Dispõe sobre normas para licenciamento de estabelecimentos processadores, registro e comercialização de produtos artesanais comestíveis de origem animal e vegetal no Estado do Pará, e dá outras providências. Diário Oficial do Estado do Pará, Belém, 26 out. 2011.
PARAIBA. Lei $n^{\circ} 11.346$, de 06 de junho de 2019. Institui o sistema de produção e comercialização de Queijos e Manteigas artesanais do estado da Paraíba. Diário Oficial do Estado do Paraiba, João Pessoa, 7 jun. 2019.

PARANÁ. Lei no 19.599, 17 de julho de 2018. Dispõe sobre a produção e a comercialização dos queijos artesanais no Estado do Paraná. Diário Oficial do Estado Paraná, Curitiba, 18 jul. 2018.

PERIN, L.M.; SARDARO, M.L.S.; NERO, L.A. et al. Bacterial ecology of artisanal Minas cheeses assessed by culture-dependent and -independent methods. Food Microbiol., v.65, p.160-169, 2017.

PERNAMBUCO. Lei ${ }^{\circ} 13.376$, de 20 de dezembro de 2007. Dispõe sobre o processo de produção artesanal do Queijo Coalho e outros produtos derivados do leite. Diário Oficial do Estado de Pernambuco, Recife, 21 dez. 2007.

PERNAMBUCO. Lei $\mathrm{n}^{\circ} 16.312$, de 11 de janeiro de 2018. Altera a Lei $\mathrm{n}^{\circ} 13.376$, de 20 de dezembro de 2007, que dispõe sobre o processo de Produção do Queijo Artesanal e dá outras providências, a fim de incluir o queijo de manteiga, a manteiga de garrafa e o doce de leite no processo de produção artesanal. Diário Oficial do Estado de Pernambuco, Recife, 12 jan. 2018.

PINTO, L.G.; BATISTA, A.P.; CÉSAR, A.S. Indicação Geográfica: o caso do queijo Alagoa - em Alagoa, Minas Gerais. In: CONGRESSO DA SOCIEDADE BRASILEIRA DE ECONOMIA, ADMINISTRAÇÃO E SOCIOLOGIA RURAL JOÃO PESSOA, 53., 2015, João Pessoa. Anais... João Passoa: SOBER, 2015.

PRODUÇÃO e vendas dos produtos e/ou serviços industriais, segundo as classes de atividades e os produtos. Rio de Janeiro: IBGE, 2017. Disponível em: <https://sidra.ibge.gov.br/Tabela/6618\#resultado> Acessado em: 25 out. 2019.

QUEIJO Minas Artesanal. Belo Horizonte: IMA, 2019. Disponível em: <http://www.ima.mg.gov.br/certificacao/queijo-minasartesanal>. Acessado em: 20 out. 2019.

RIO GRANDE DO NORTE. Decreto 27.683, de 26 de janeiro de 2018. Regulamenta a Lei Estadual no 10.230 , de 7 de agosto de 2017, que trata da produção e da comercialização de queijos e manteiga artesanais do Rio Grande do Norte - Lei Nivardo Mello, e dá outras providências. Diário Oficial do Estado do Rio Grande do Norte, Natal, 26 jan. 2018a.

RIO GRANDE DO NORTE. Decreto 28.012, de 30 de maio de 2018. Altera o Decreto Estadual n ${ }^{\circ} 27.683$, de 26 de janeiro de 2018, que regulamentou a Lei Estadual $\mathrm{n}^{\circ} 10.230$, de 7 de agosto de 2017 , que trata da produção e da comercialização de queijos e manteiga artesanais do Rio Grande do Norte - Lei Nivardo Mello. Diário Oficial do Estado do Rio Grande do Norte, Natal, 31 maio $2018 \mathrm{~b}$ 
RIO GRANDE DO NORTE. Lei $\mathrm{n}^{\circ} 10.230$, de 07 de agosto de 2017. Dispõe sobre a produção e a comercialização de queijos e manteiga artesanais do rio grande do norte - Lei nivardo mello. Diário Oficial do Estado do Rio Grande do Norte, Natal, 8 ago. 2017.

RIO GRANDE DO SUL. Decreto $n^{\circ} 54.199$, de 24 de agosto de 2018. Dispõe sobre a produção e a comercialização do queijo artesanal serrano no Estado do Rio Grande do Sul. Diário Oficial do Estado do Rio Grande do Sul, Porto Alegre, 27 ago. 2018.

RIO GRANDE DO SUL. Lei $\mathrm{n}^{\circ} 14.973$, de 29 de dezembro de 2016. Dispõe sobre a produção e a comercialização do queijo artesanal serrano no Estado do Rio Grande do Sul. Diário Oficial do Estado do Rio Grande do Sul, Porto Alegre, 30 dez. 2016. n. ${ }^{\circ} 249$.

RIOGRANDE DO SUL. Secretaria da Agricultura, Pecuária e Desenvolvimento Rural. Instrução Normativa ${ }^{\circ} 10$, de 29 agosto de 2019. Diário Oficial do Estado do Rio Grande do Sul, Porto Alegre, 5 set. 2019.

RONDÔNIA. Lei no 4.671, de 06 de dezembro de 2019. Dispõe sobre a produção e comercialização de queijos artesanais de leite cru e adota outras providências. Diário Oficial do Estado de Rondônia, Porto Velho, 6 dez. 2019.

SALES, G.A. Caracterização microbiológica e físicoquímica de Queijo Minas Artesanal da microrregião de Araxá - MG durante a maturação em diferentes épocas do ano. 2015. 106f. Dissertação (Mestrado) - Escola de Veterinária, Universidade Federal de Minas Gerais, Belo Horizonte, MG.

SANTA CATARINA. Decreto ${ }^{\circ} 1238$, de 19 de julho de 2017. Regulamenta a Lei $n^{\circ} 17.003$, de $1^{\circ}$ de setembro de 2016. Governo do Estado de Santa Catarina, Florianópolis, 20 jul. 2017.
SANTA CATARINA. Lei $\mathrm{n}^{\circ} 17.003$, de $1^{\circ}$ de setembro de 2016. Dispõe sobre a produção e a comercialização do queijo artesanal serrano, no Estado de Santa Catarina. Diário Oficial do Estado de Santa Catarina, Florianópolis, 02 de setembro de 2016.

SANTA CATARINA. Lei $\mathrm{n}^{\circ} 17.486$, de 15 de janeiro de 2018. Dispõe sobre a produção e comercialização de queijos artesanais de leite cru e adota outras providências. Diário Oficial do Estado de Santa Catarina, Florianópolis, 17 jan. 2018.

SANTIAGO, D.G.; JUNIOR, E.A.B.; GASPAR, L.C.M.; SARAIVA, P.M. Ministério da Agricultura e o Fomento as Indicações Geográficas no Brasil. In: BAGATINI, F.Z. (Ed.). Indicações geográficas, signos coletivos e desenvolvimento local/regional erechim, Rio Grande do Sul: Deviant, 2019. v.2, cap.3, p.73-98.

SANTOS FILHO, A.S.; PIRES, C.V; CARDOSO, W.J. et al. Caracterização física e condições sanitárias do comércio de queijo cabacinha em três municípios do Vale do Jequitinhonha, MG, Brasil. Rev. Inst. Latic. Cândido Tostes, v.71, 219-227, 2016.

SERGIPE. Lei $n^{\circ} 8.523$, de 29 de abril de 2019. Dispõe normas sobre a produção e a comercialização dos queijos artesanais (tradicional e inovação) no Estado de Sergipe, e dá providências correlatas. Diário Oficial do Estado de Sergipe, Aracaju, 30 abr. 2019.

SLOW-FOOD Foundation for Biodiversity Online. 2019. Available in: <https://www.fondazioneslowfood.com/en/nazioniarca/brazil-en/?fwp_arca_settore=milk-and-milkproducts-en >. Accessed in: 20 Jun. 2019.

SOUTHEY, R. History of Brazil. Londres: Longman, 1819.

SOUTHEY, R. History of Brazil: part the first. London: Longman, 1810. v.1, p.659. 